\title{
Макєঠovıкá
}

Tóp. 36 (2007)

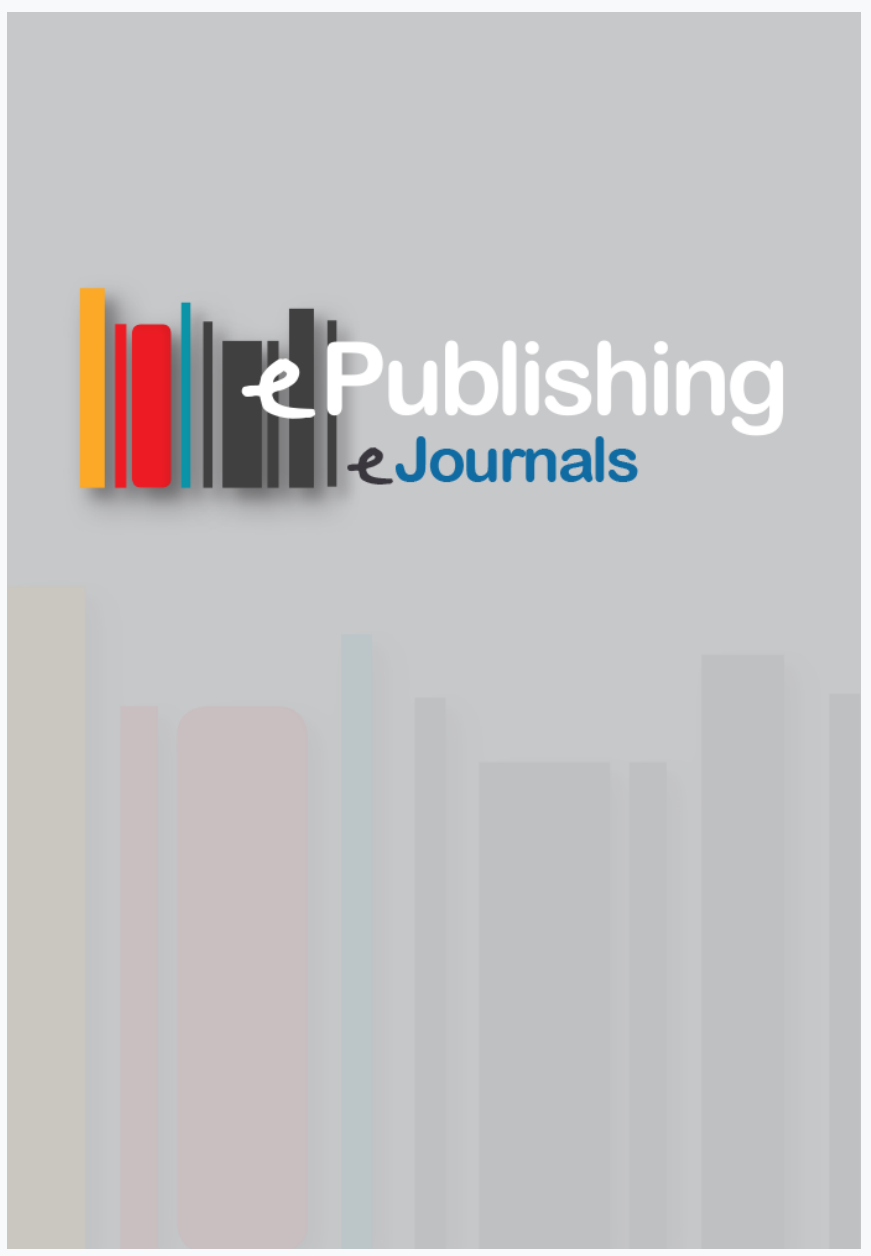

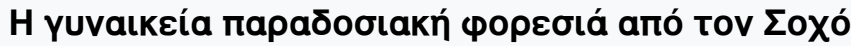

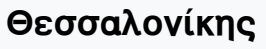

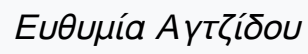

doi: $10.12681 /$ makedonika.32

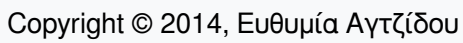

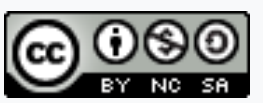

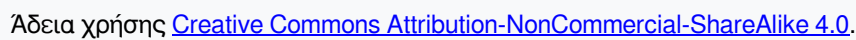

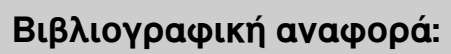

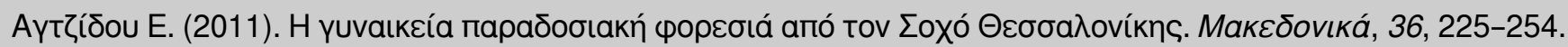
https://doi.org/10.12681/makedonika.32 


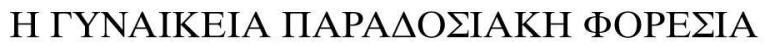 AПO TON $\Sigma$ OXO $\Theta E \Sigma \Sigma A \Lambda O N I K H \Sigma$ ПРЯТН ПРОГЕГГІ $\mathrm{H}$}

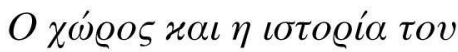

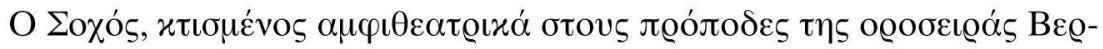

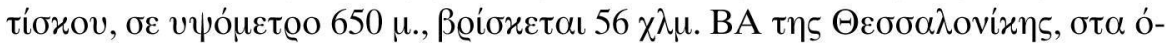

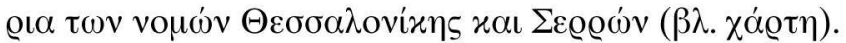

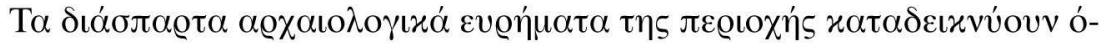

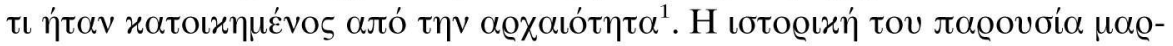

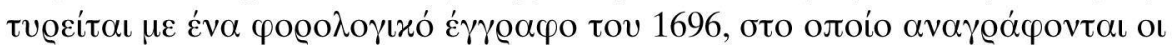

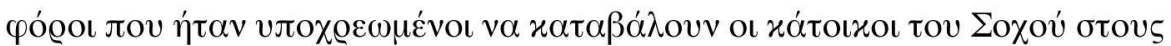

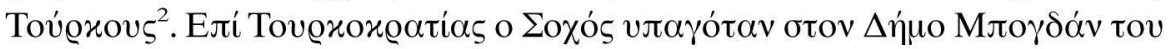

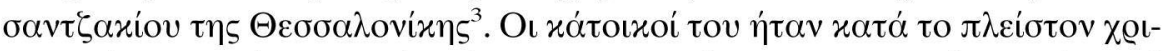

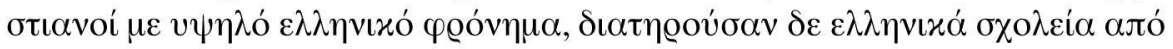

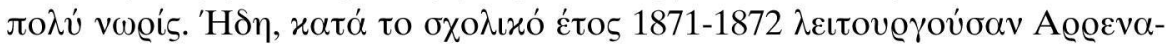

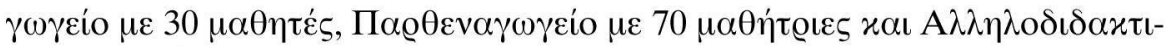

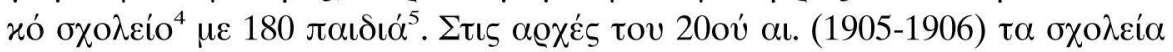

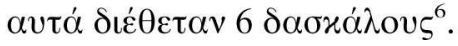

1. П@ß. Esprit-Marie Cousinery, Voyage dans la Macédoine: contenant des recherches sur l'histoire, la géographie et les antiquités de ce pays, v. 2, Paris, Imprimerie Royale, 1831, бo. 5657. William Martin Leake, Travels in Northern Greece, v. 3, London, J. Bodwell, 1835, бo. 229-

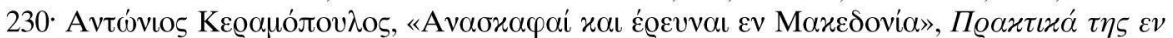

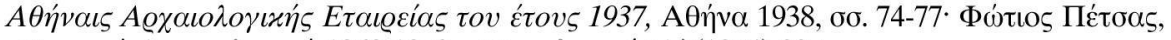

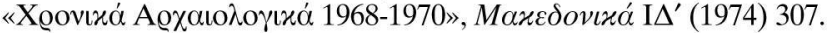

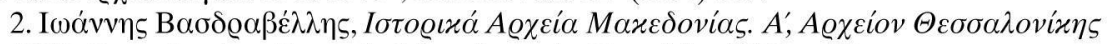

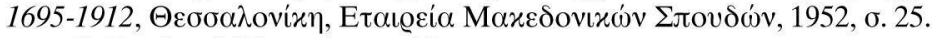

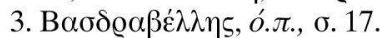

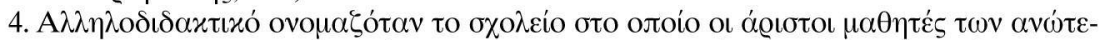

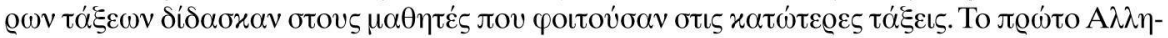

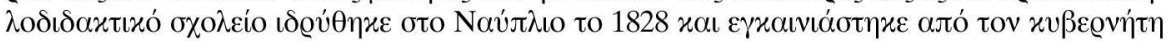

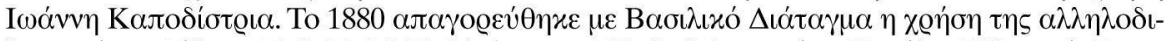

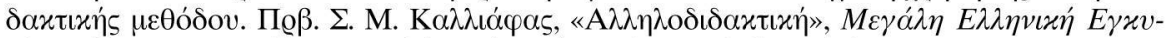

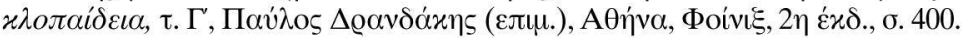

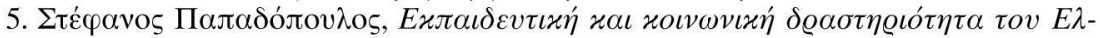

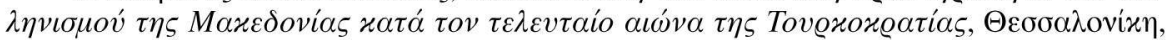

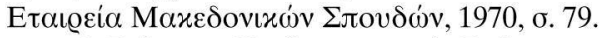

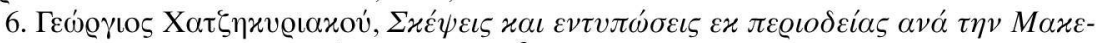

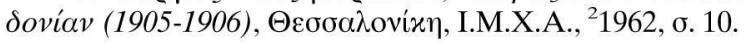




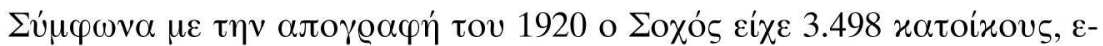

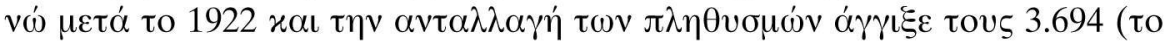

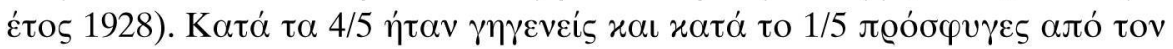

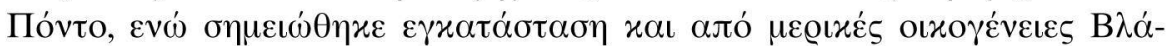

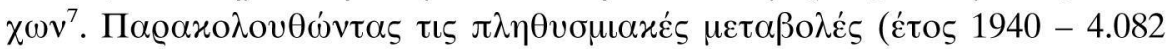

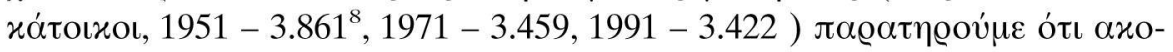

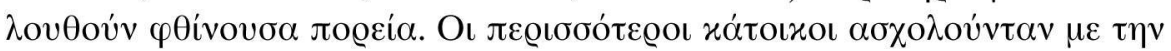

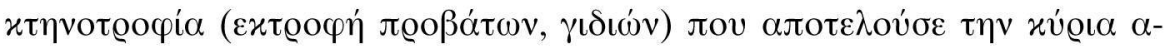

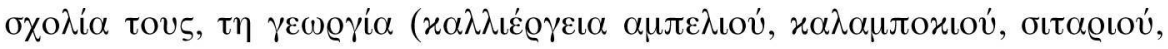

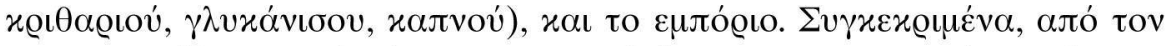

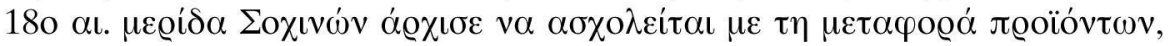

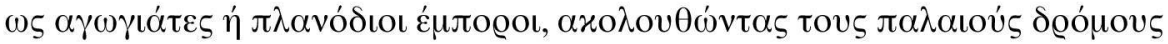

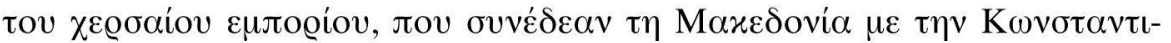

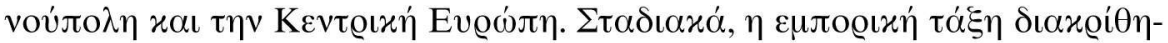

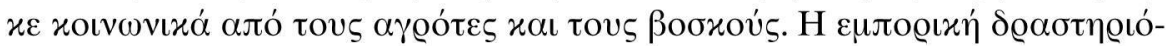

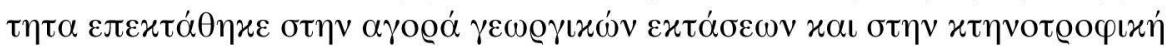

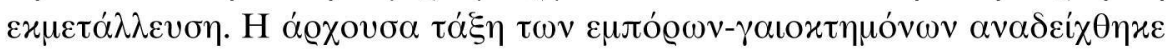

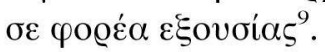

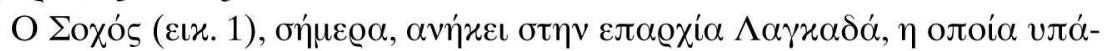

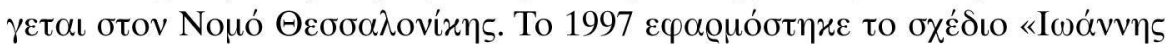

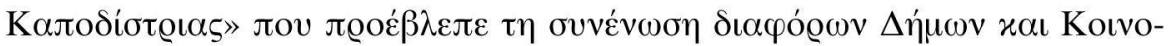

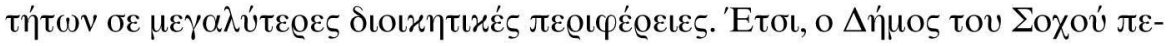

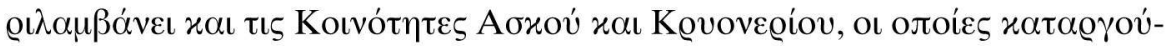
vтаı.

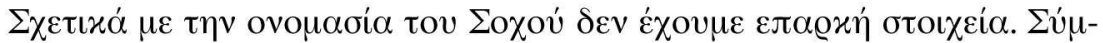

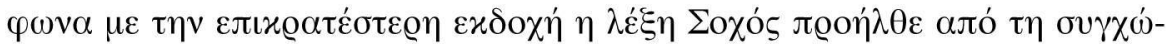

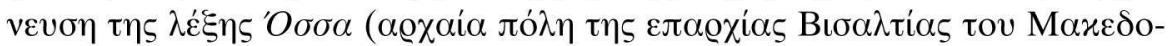

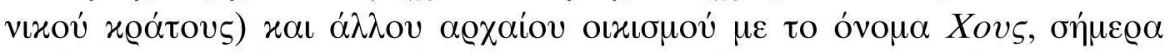

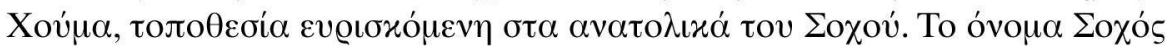

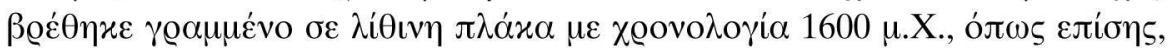

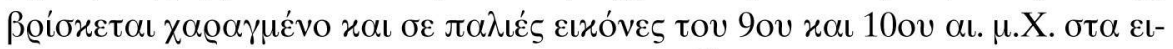

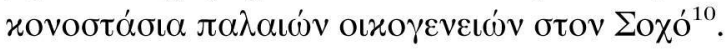

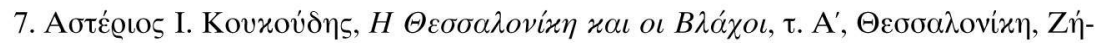

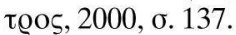

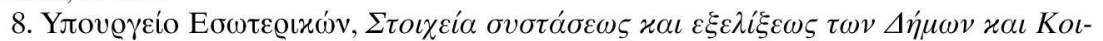

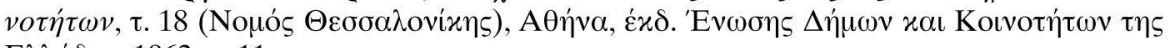

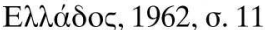

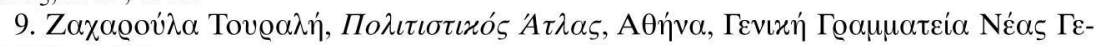
vıós, 2000, б. 230.

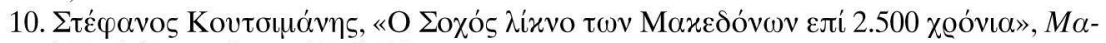

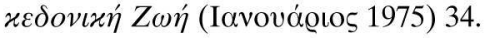




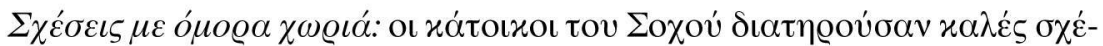

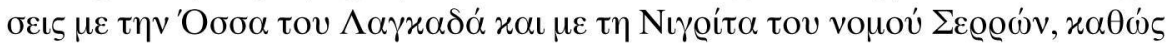

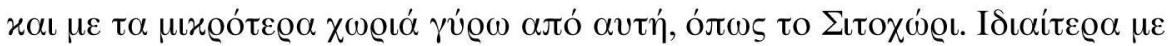

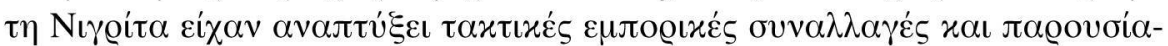

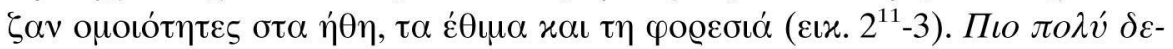

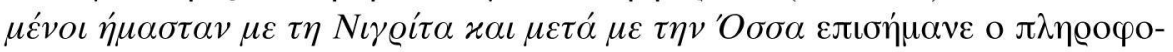

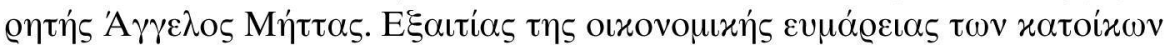

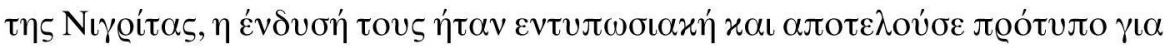

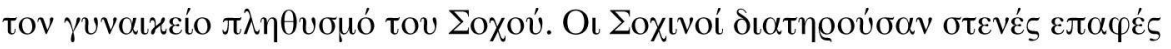

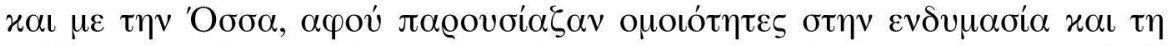

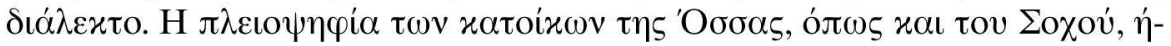

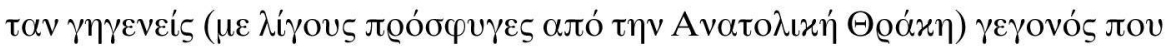

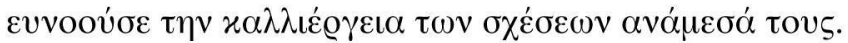

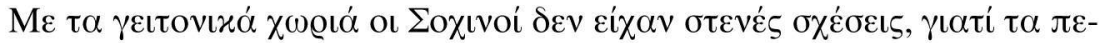

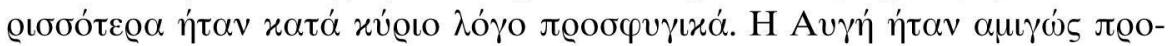

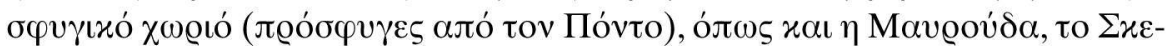

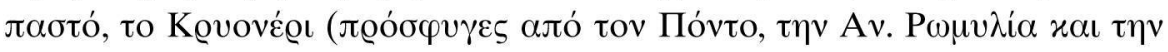

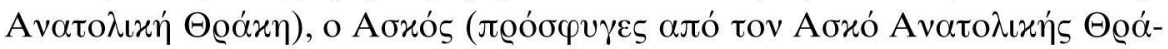

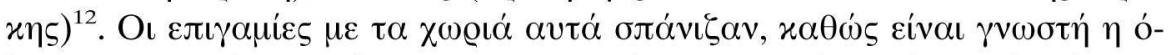

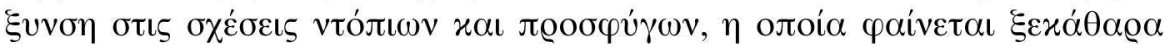

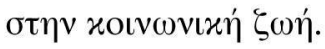

\section{$H$ ć@evva}

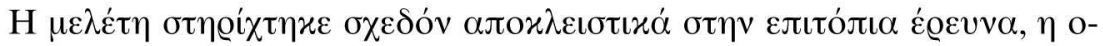

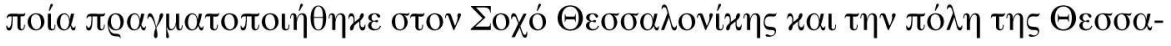

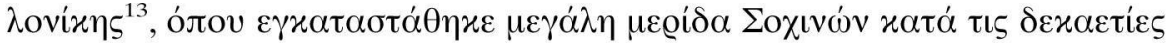

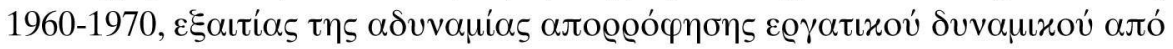

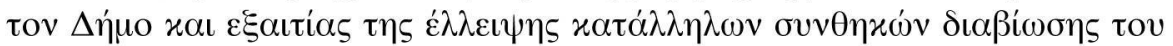
$\pi \lambda \eta \theta v \sigma \mu o v ́$.

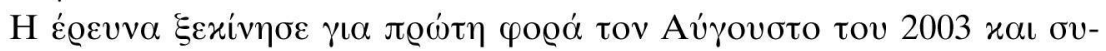

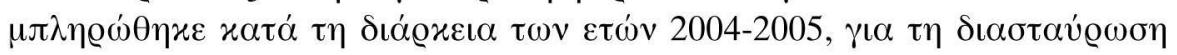

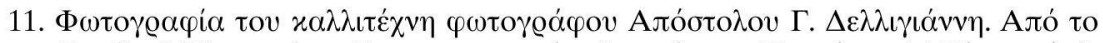

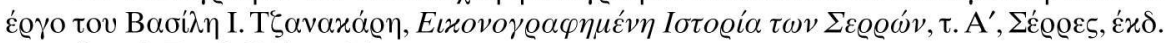

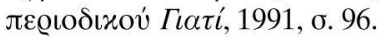

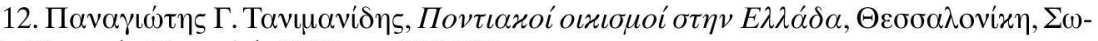

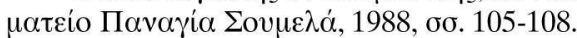

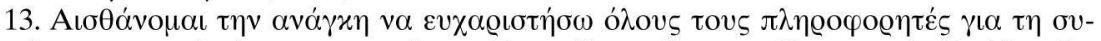

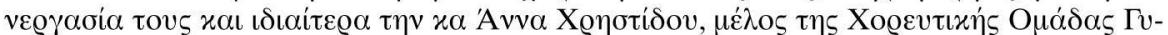

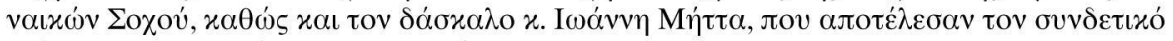

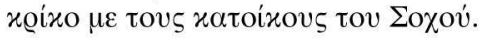




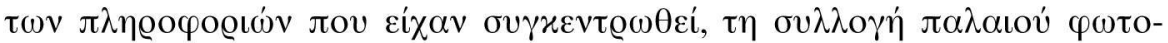

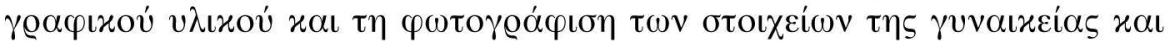

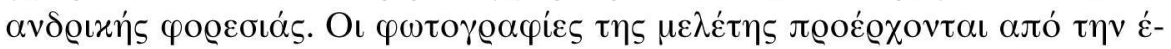

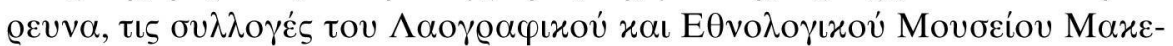

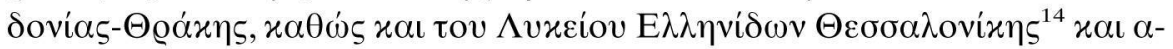

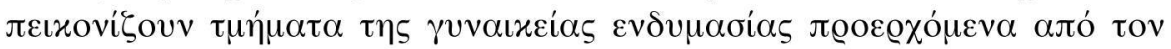
इoxó.

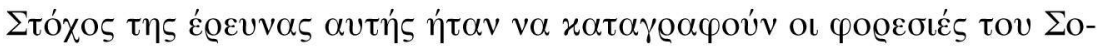

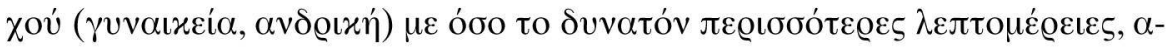

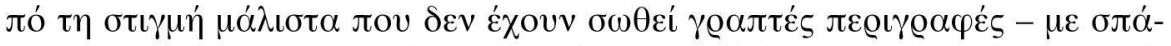

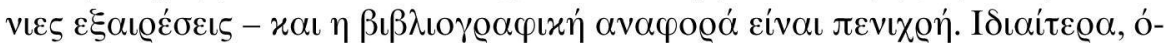

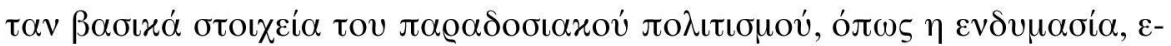

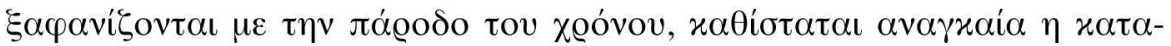

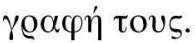

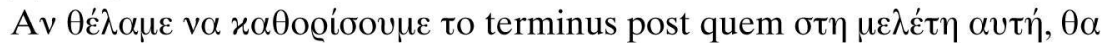

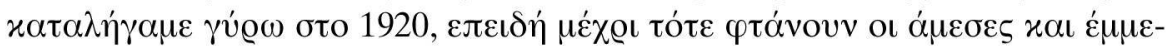

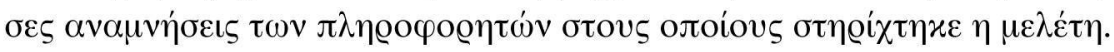

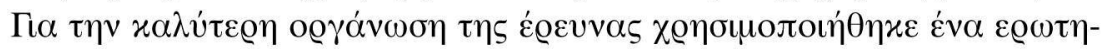

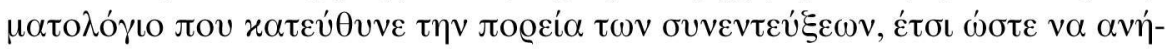

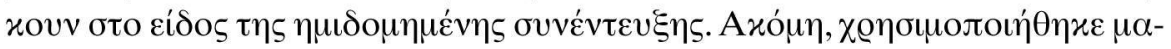

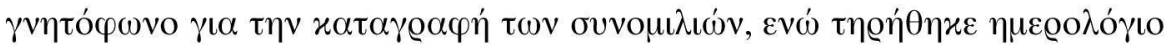

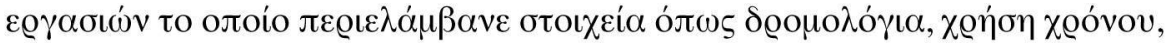

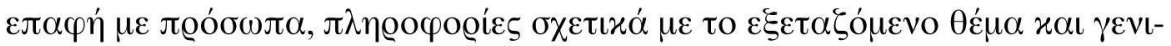

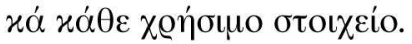

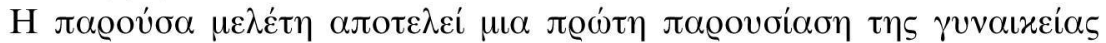

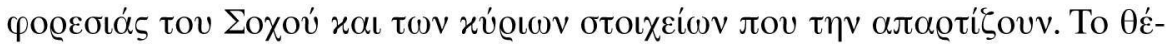

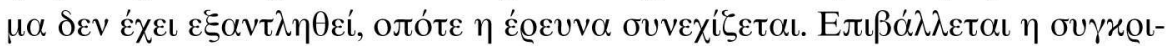

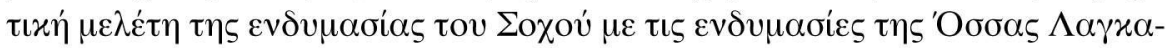

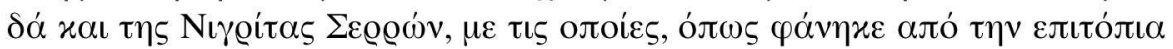

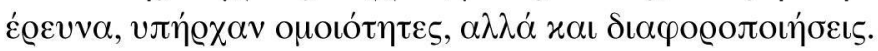

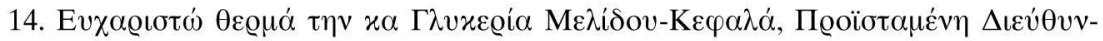

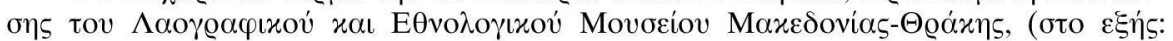

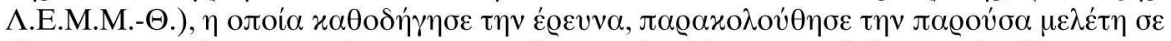

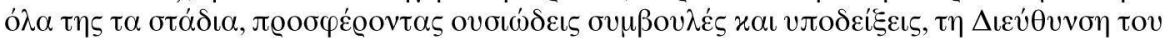

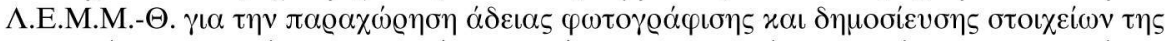

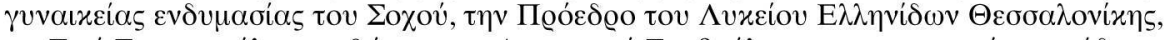

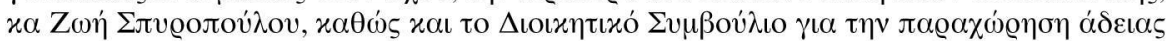

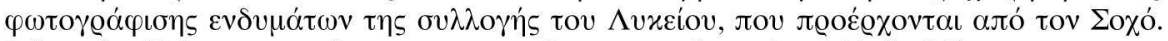

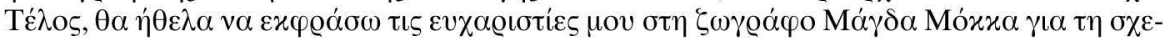

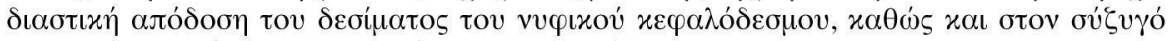

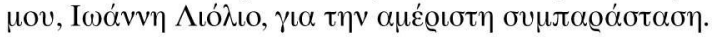




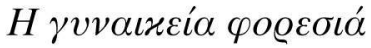

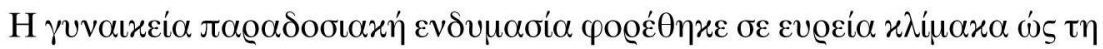

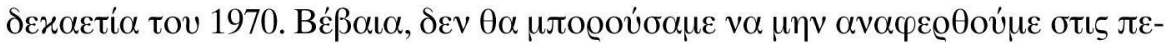

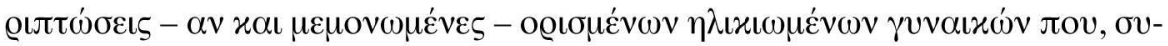

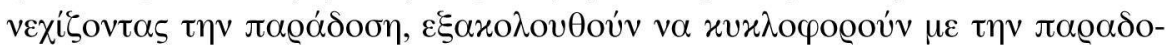

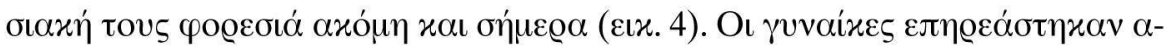

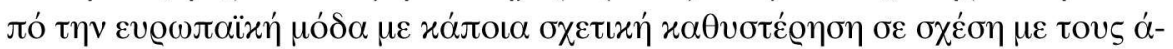

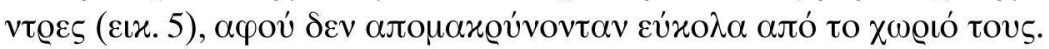

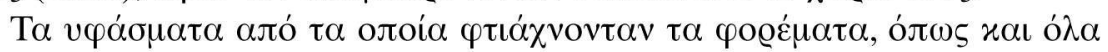

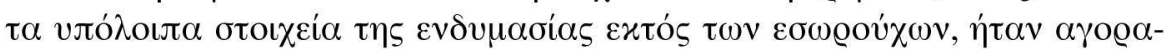

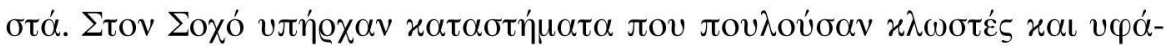

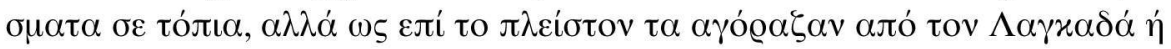

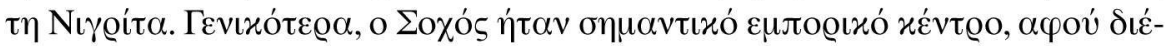

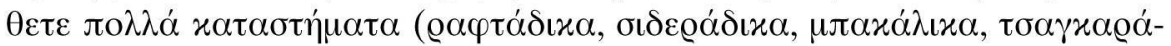

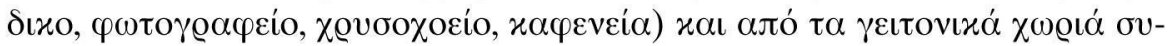

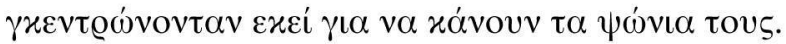

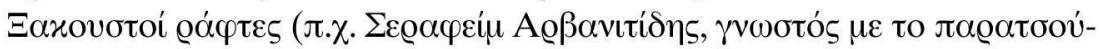

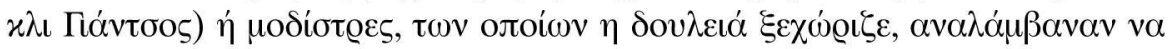

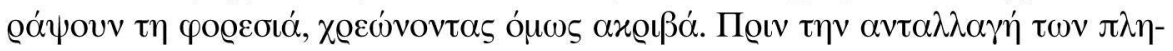

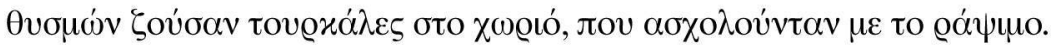

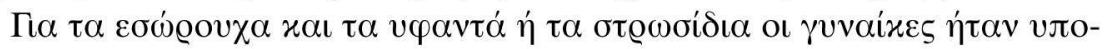

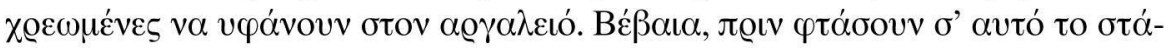

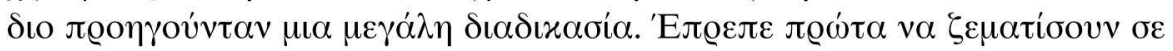

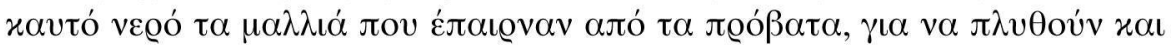

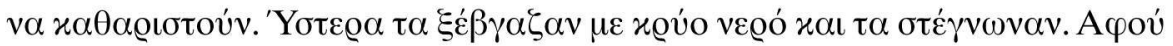

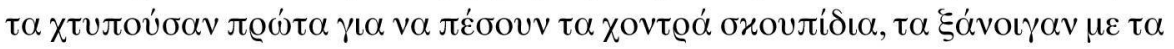

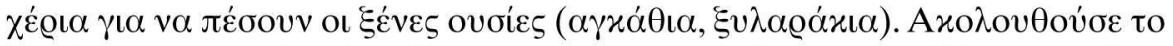

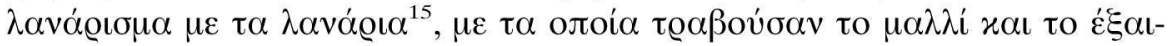

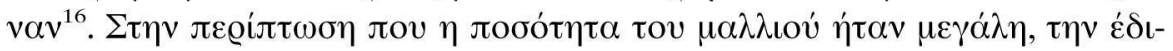

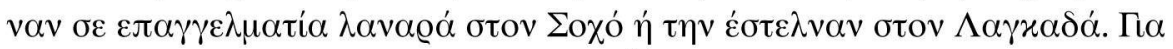

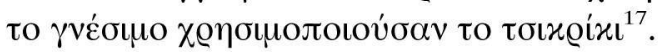

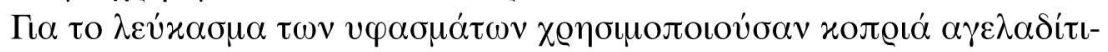

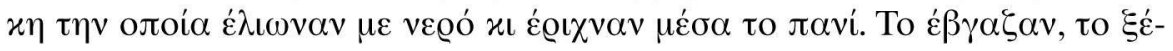

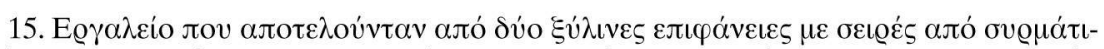

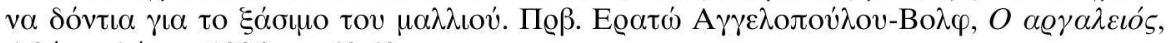

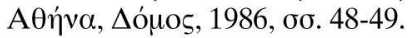

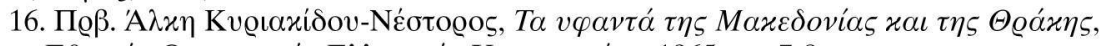

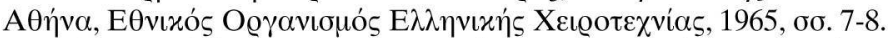

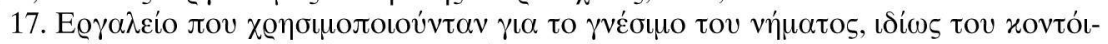

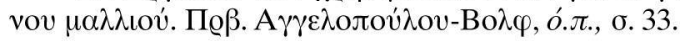




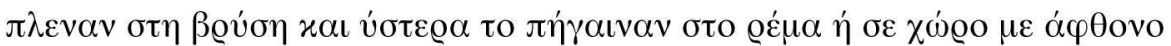

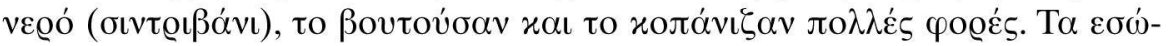

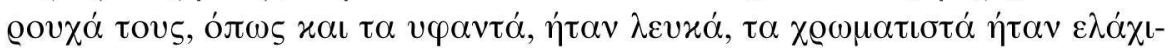
$\sigma \tau \alpha$.

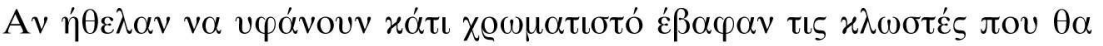

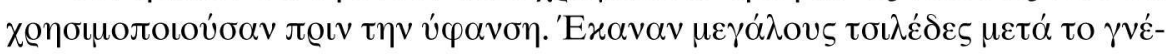

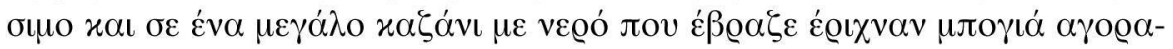

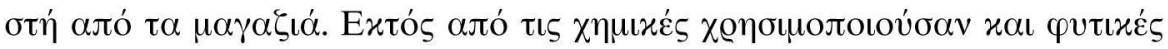

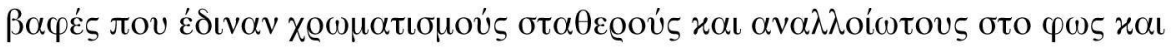

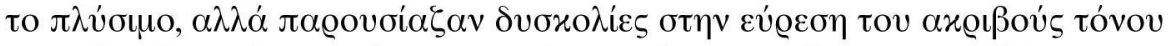

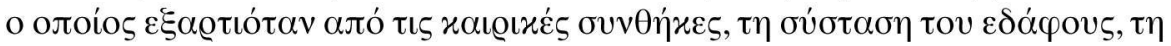

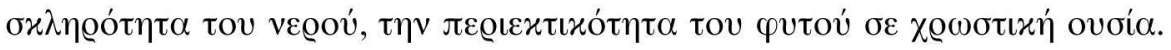

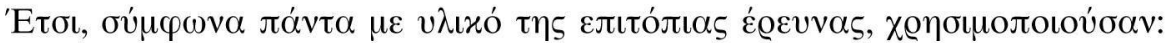

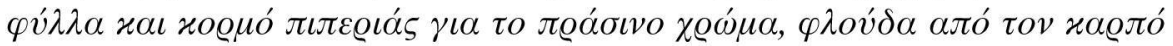

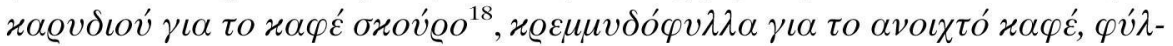

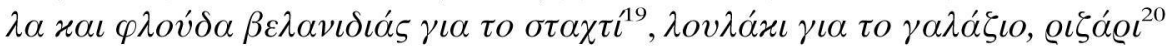

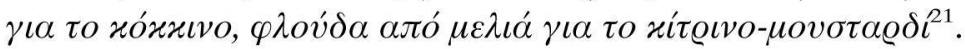

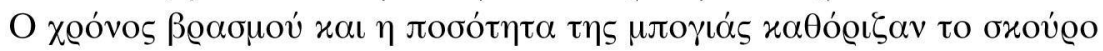

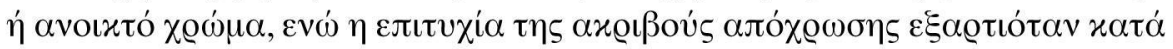

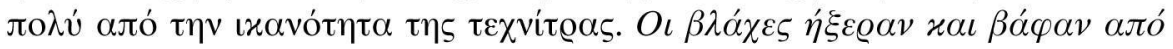

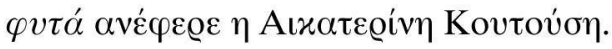

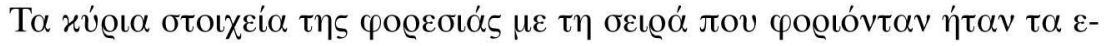

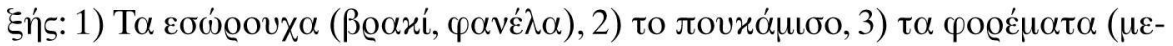

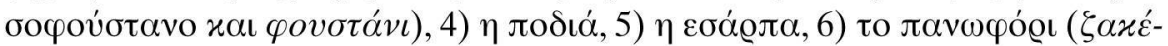

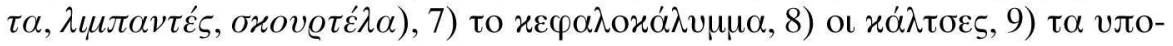

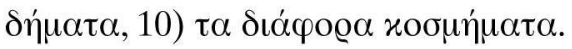

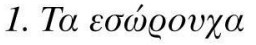

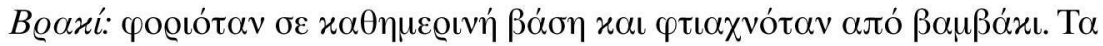

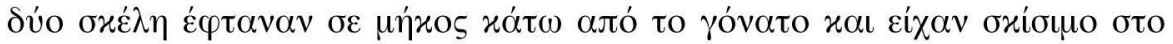

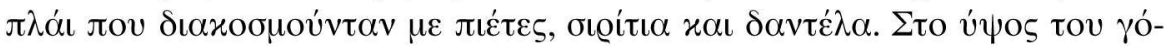

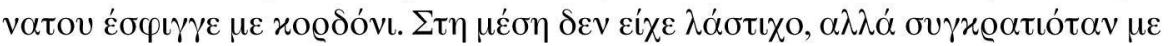

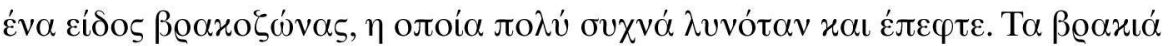

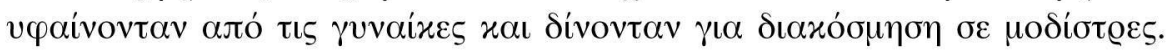

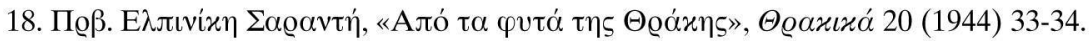

19. 'O. $\pi ., 22$.

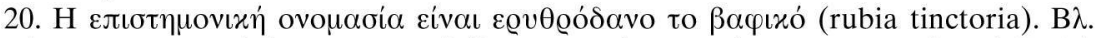

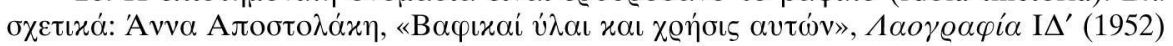
102-106.

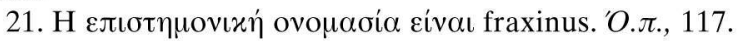




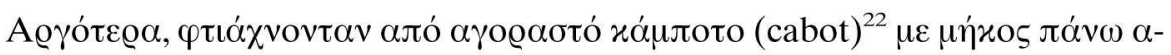

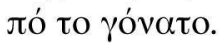

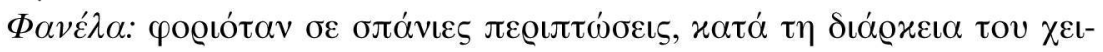

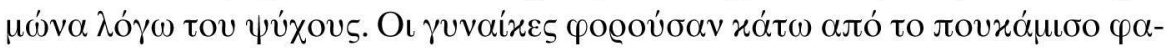

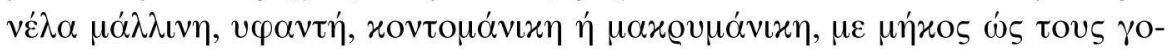
poús.

\section{2. То лочхо́цєбо}

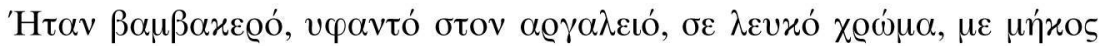

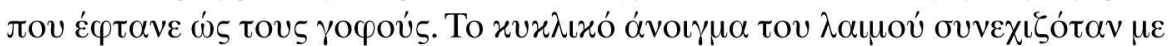

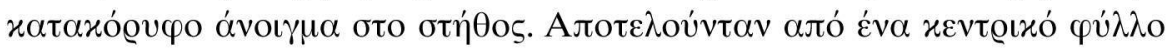

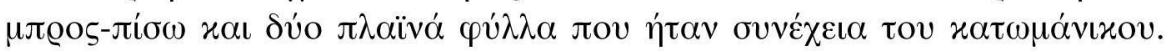

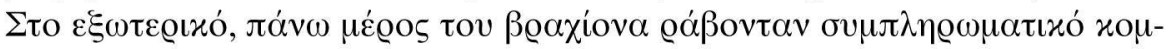

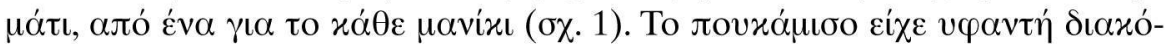

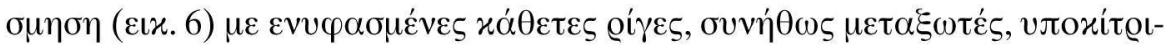

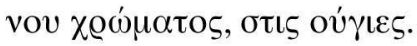

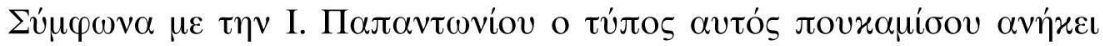

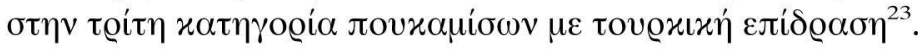

\section{3. $T \alpha \varphi \circ \varrho \varepsilon ́ \mu \alpha \tau \alpha$}

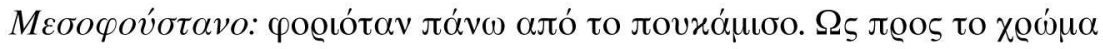

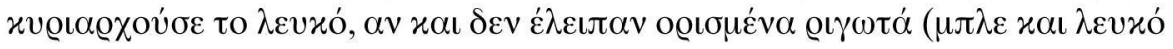

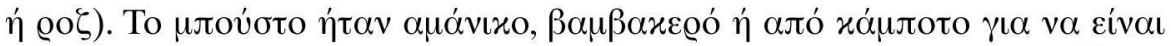

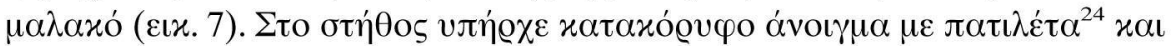

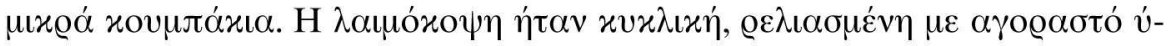

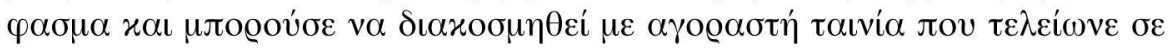

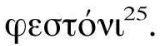

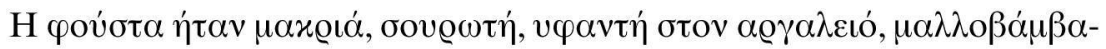

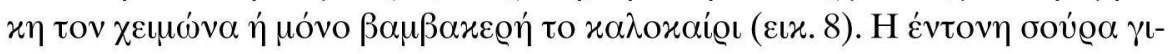

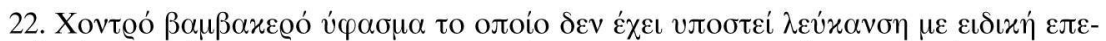

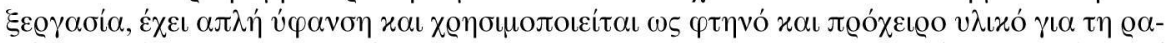

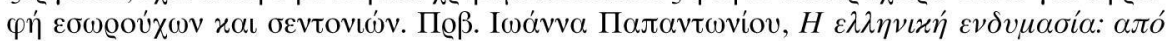

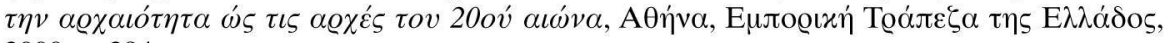
2000, б. 294

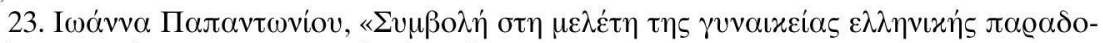

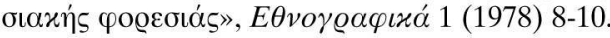

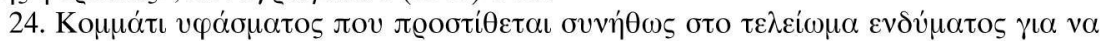

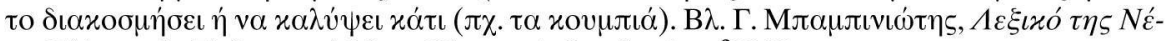

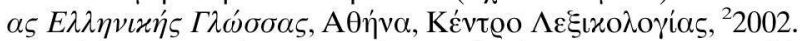

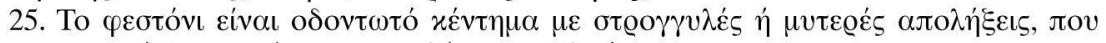

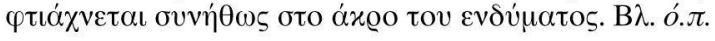




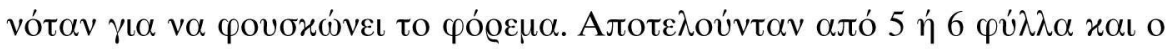

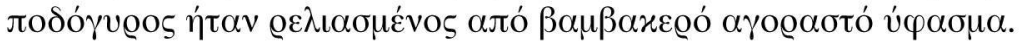

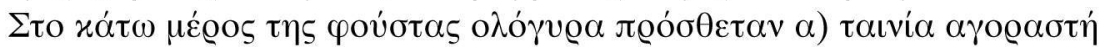

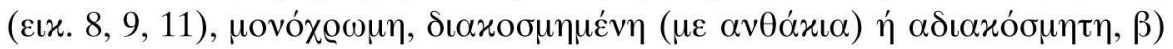

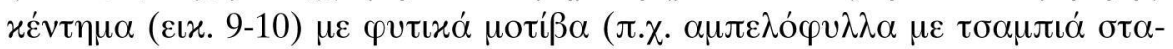
$\varphi v \lambda\llcorner o v ́)$.

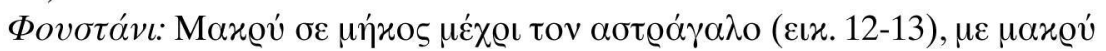

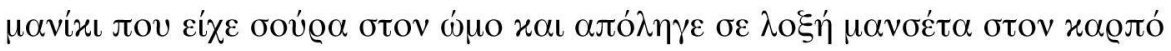

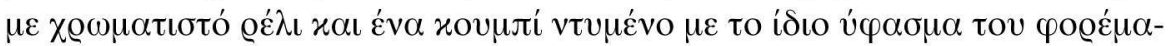

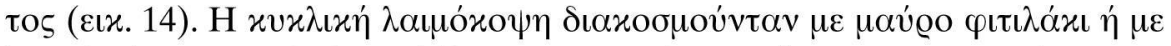

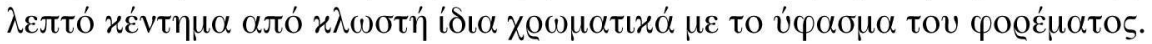

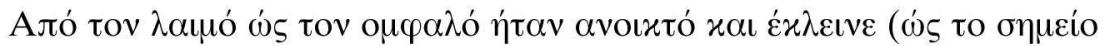

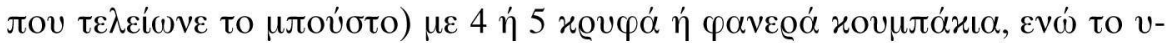

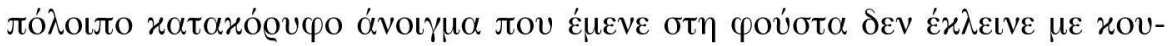

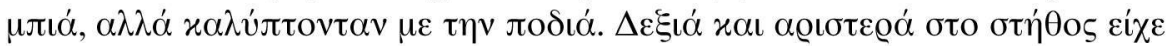

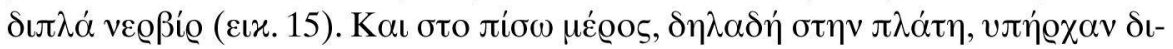

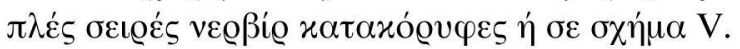

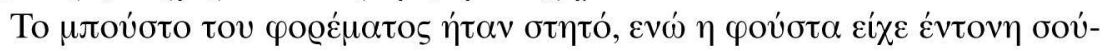

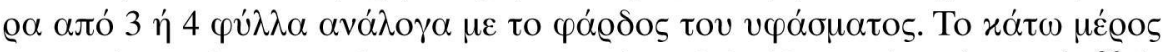

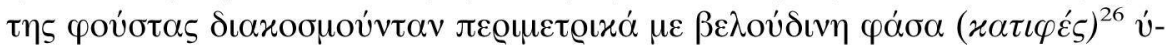

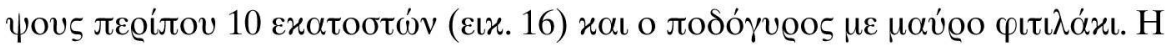

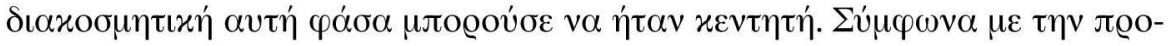

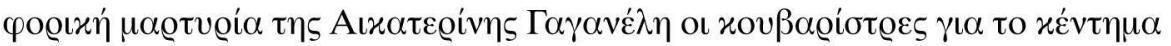

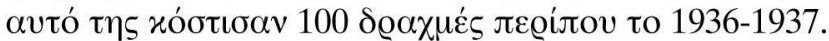

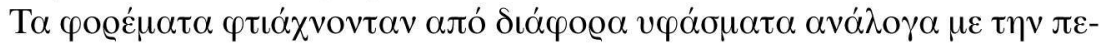

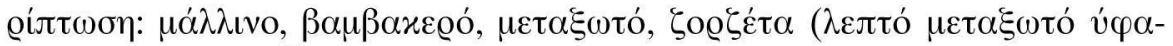

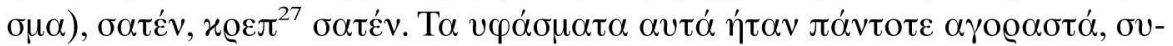

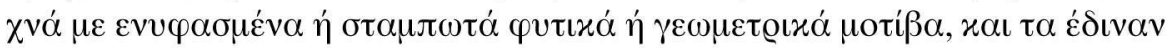

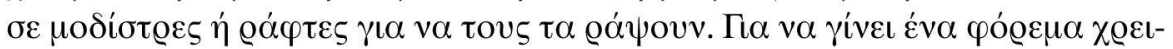

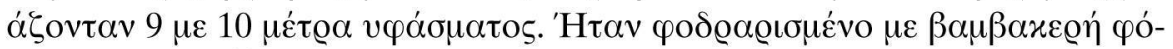

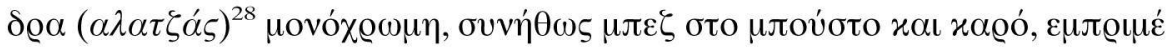

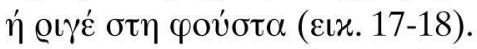

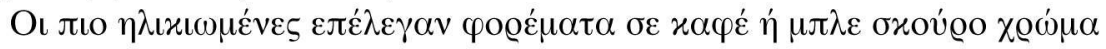

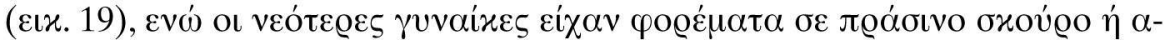

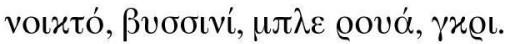

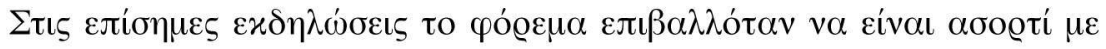

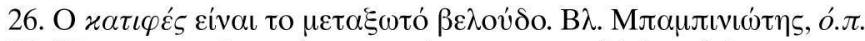

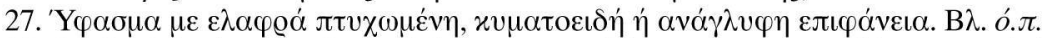

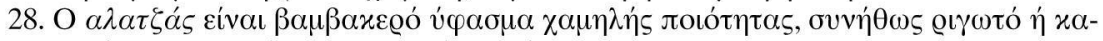

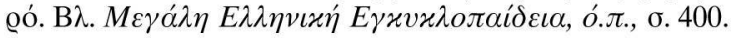




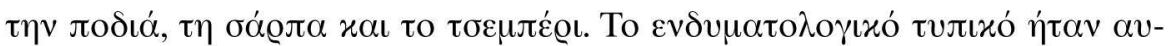

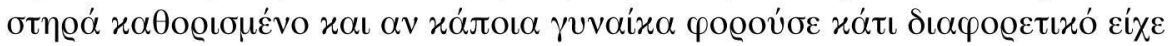

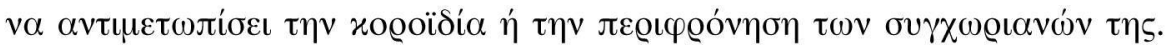

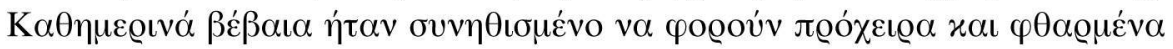

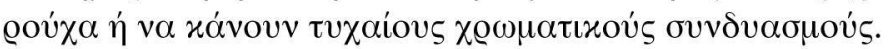

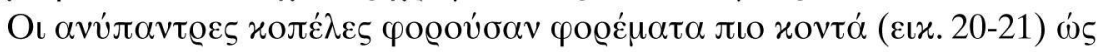

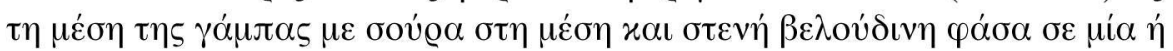

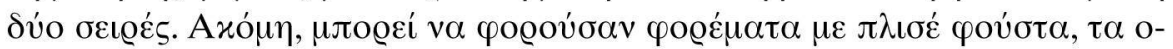

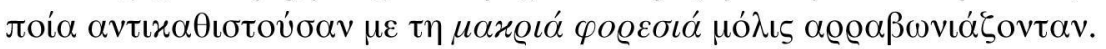

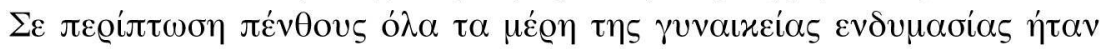

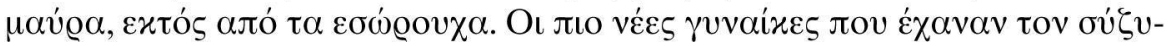

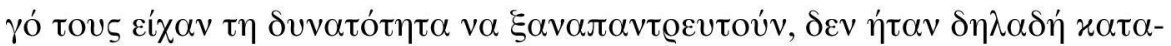

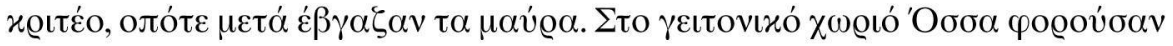

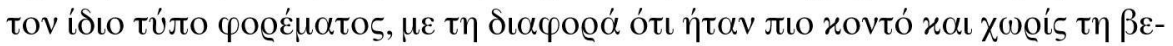

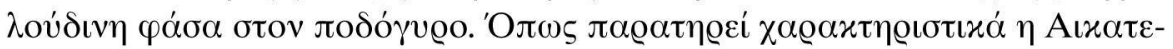

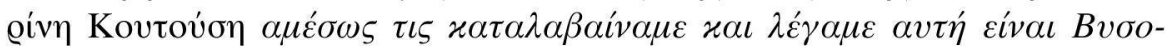
xví⿱㇒冋 ${ }^{29}$.

\section{H $\pi \circ \delta \iota \alpha$}

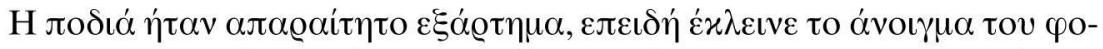

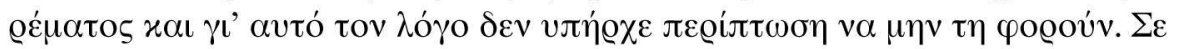

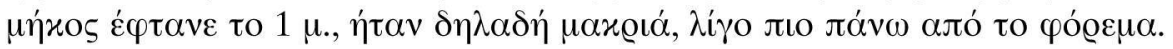

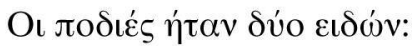

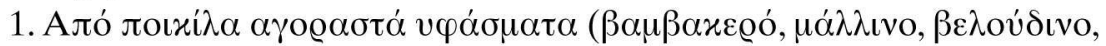

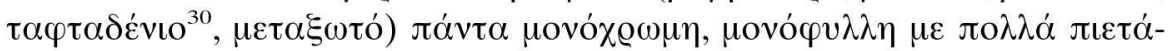

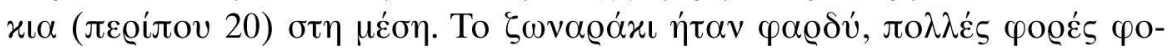

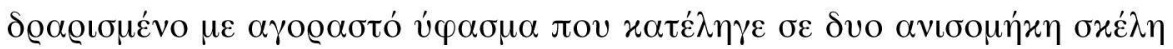

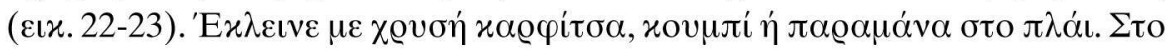

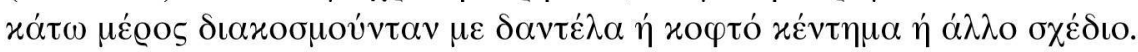

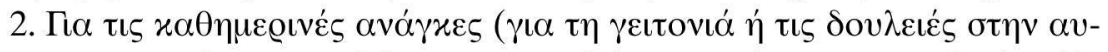

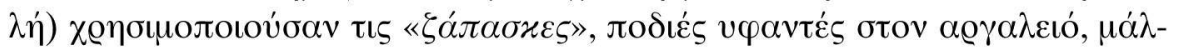

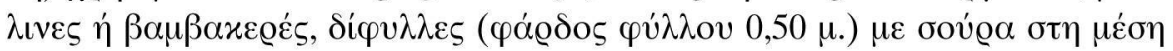

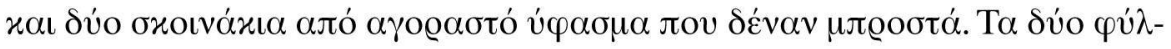

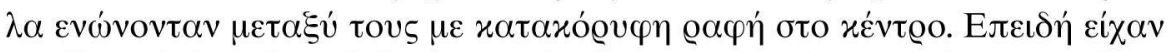

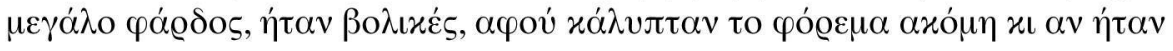

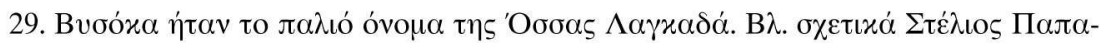

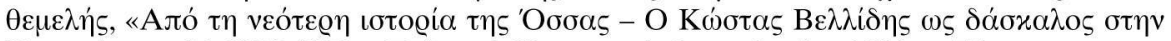

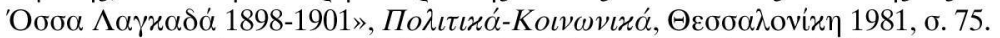

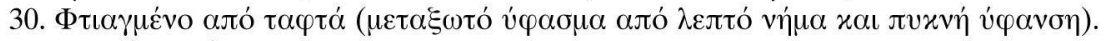

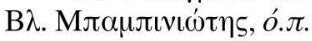


$\pi \alpha \lambda$ ıó. Oı v

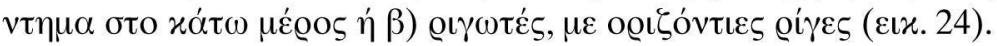

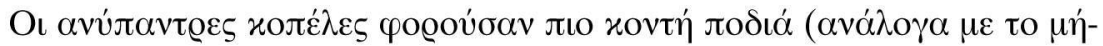

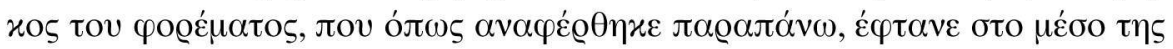

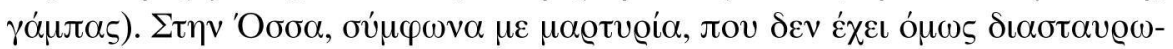

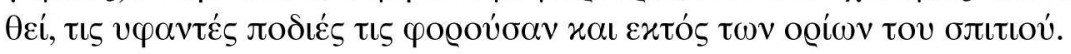

\section{5. $H \varepsilon \sigma \alpha \dot{\alpha} \propto \alpha$}

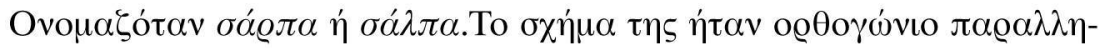
$\lambda$ ó

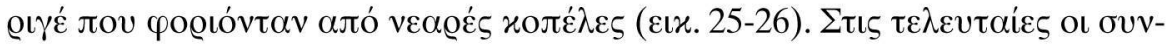

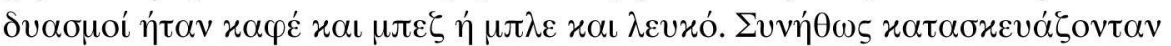

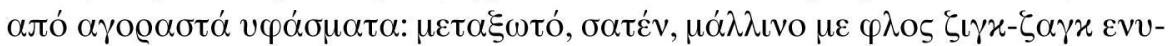

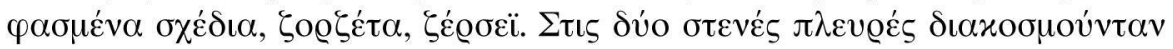

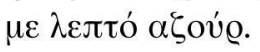

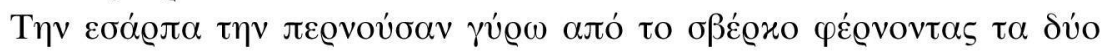

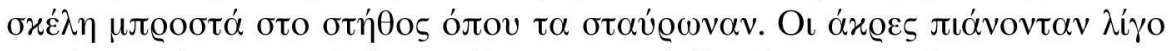

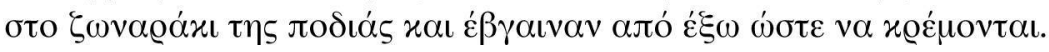

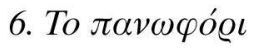

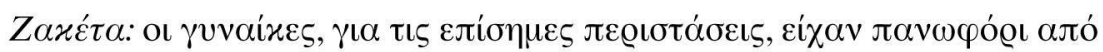

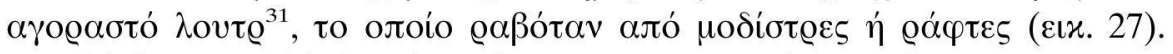

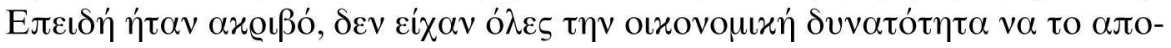

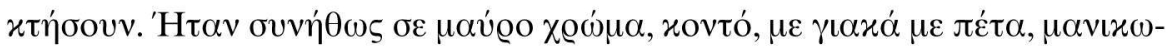

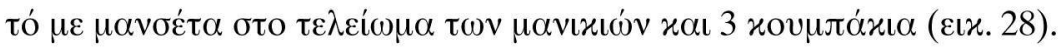

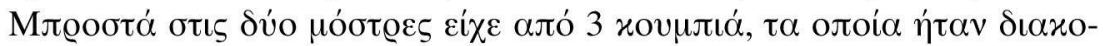

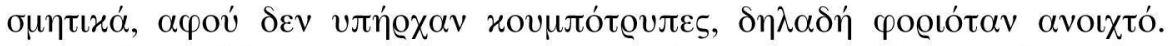

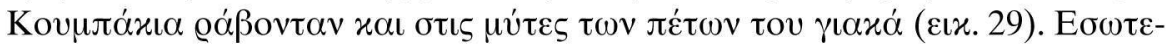

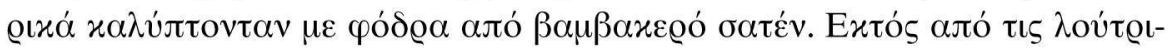

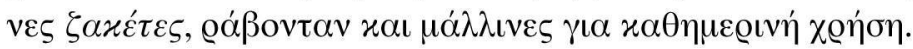

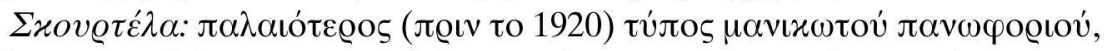

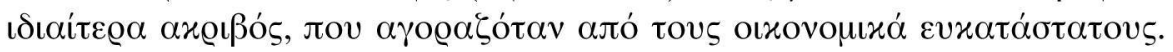

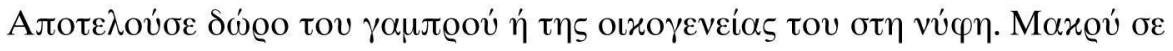

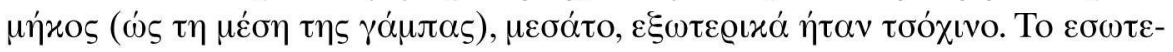

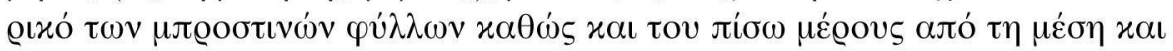

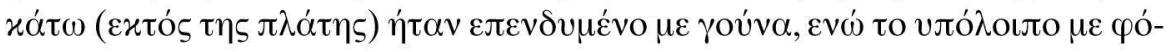

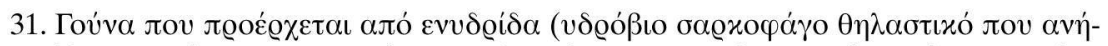

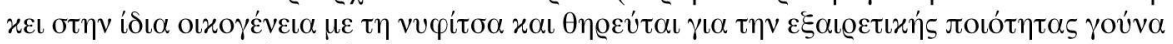

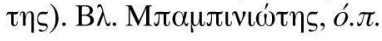




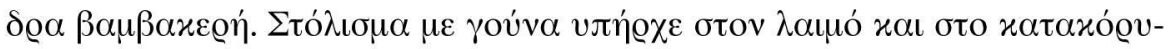

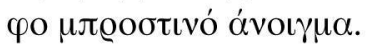

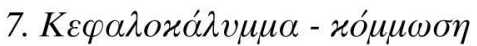

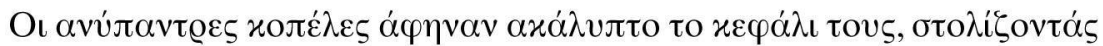

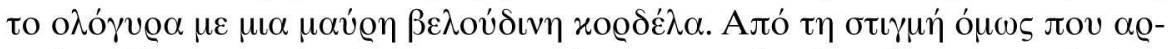

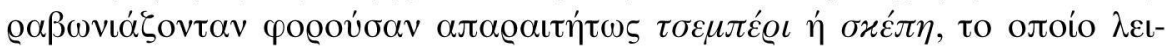

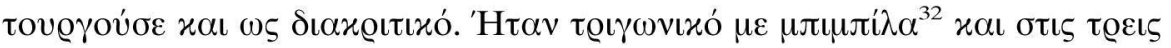

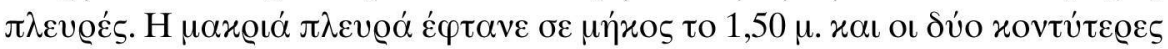

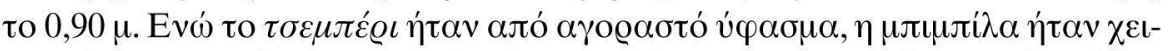

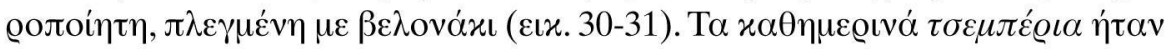

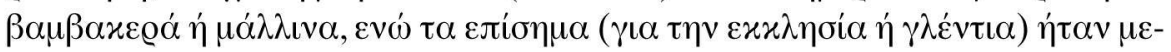
$\tau \alpha \xi \omega \tau \alpha \dot{~ . ~ K \alpha \tau \alpha ́ ~ x u ́ @ ı ~ \lambda o ́ \gamma o ~ \eta ́ \tau \alpha v ~ \mu о v o ́ \chi \varrho \omega \mu \alpha ~ \sigma \varepsilon ~ \delta เ \alpha ́ \varphi о \varrho \varepsilon \varsigma ~ \alpha л о \chi \varrho \omega ́ \sigma \varepsilon เ \varsigma, ~ o ́ л \omega \varsigma ~}$

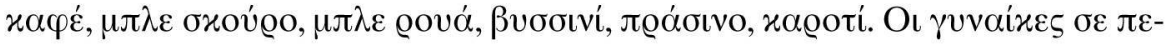

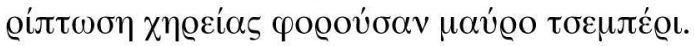

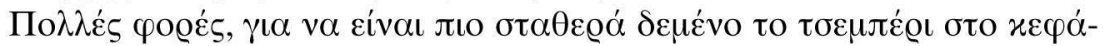

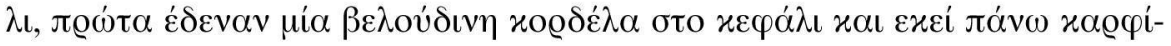

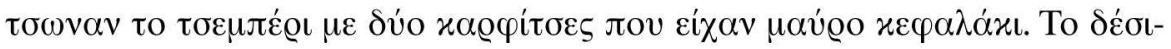

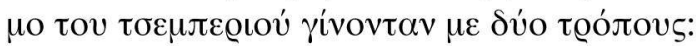

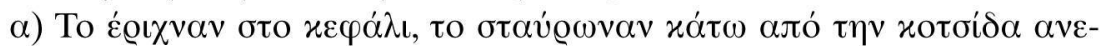

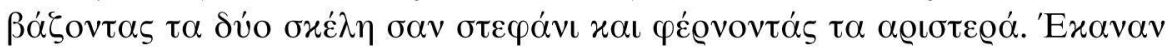

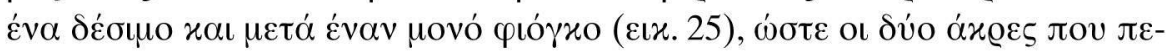

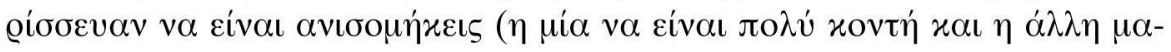
x@เ人́).

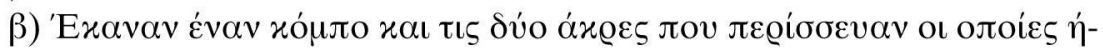

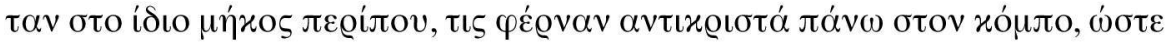

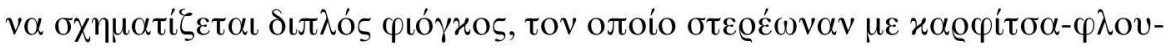
@óxt.

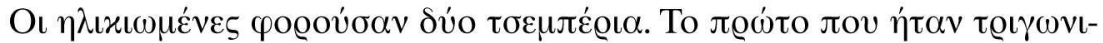

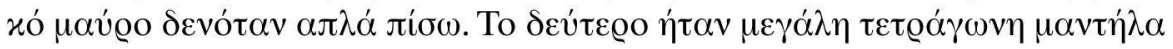

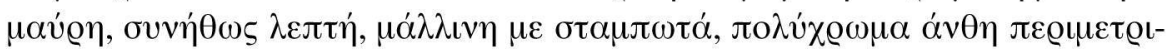

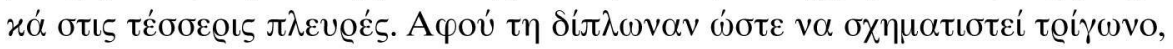

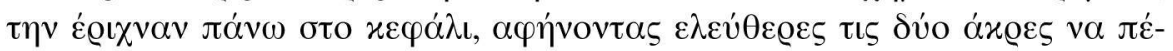

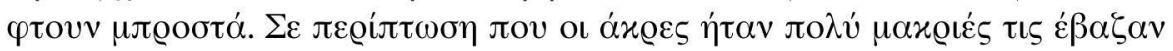

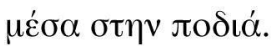

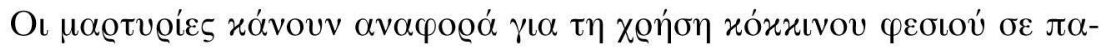

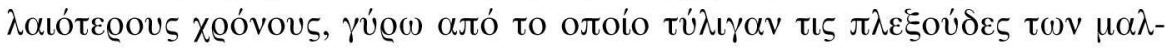

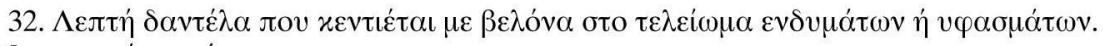

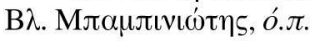




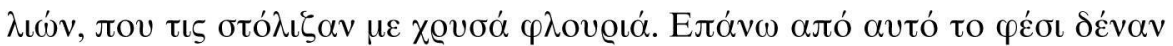

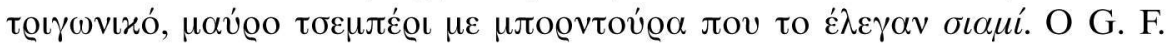

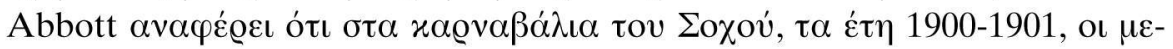

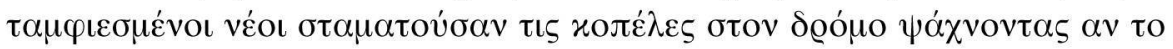

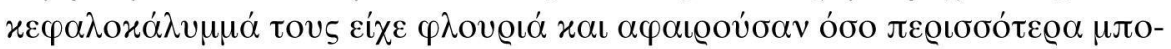

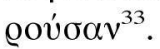

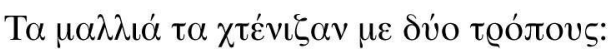

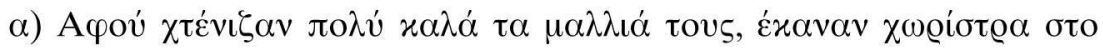

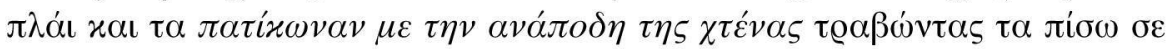

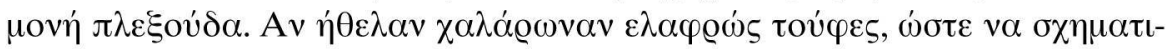

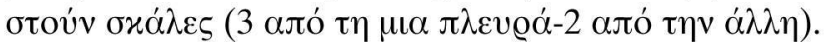

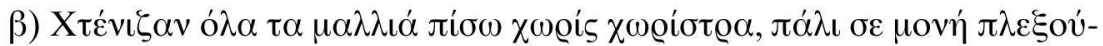

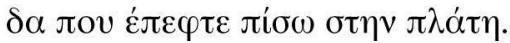

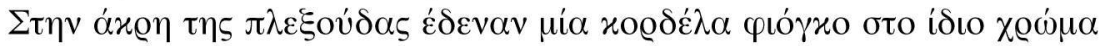

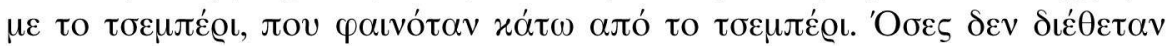

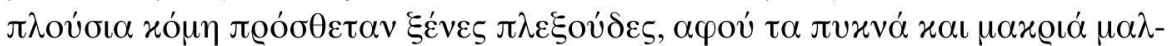

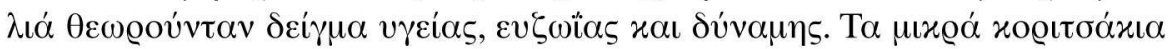
$\mu \pi$

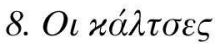

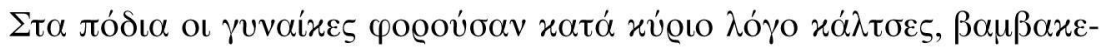

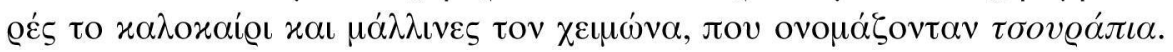

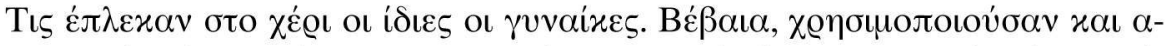

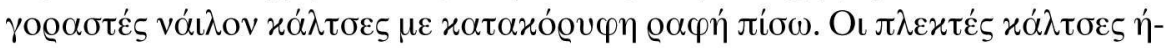

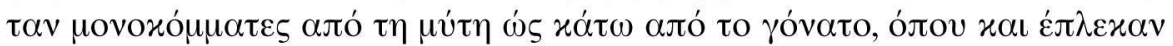

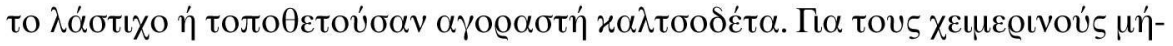

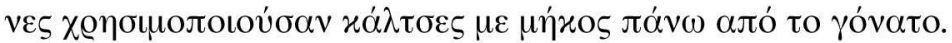

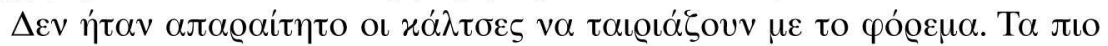

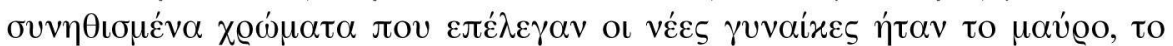

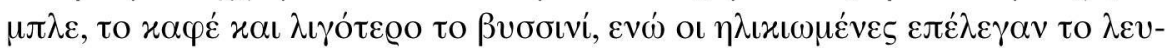

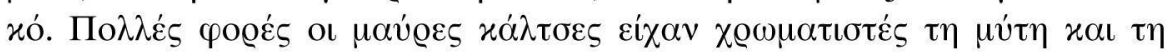

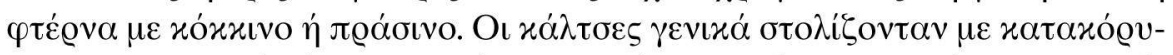

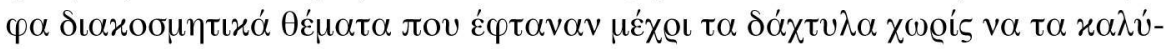

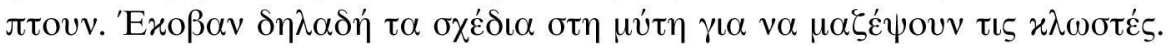

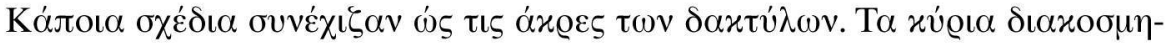

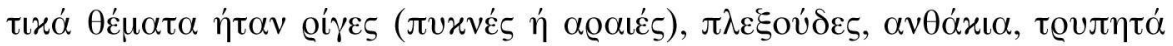

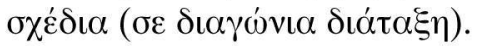

33. George Frederick Abbott, Macedonian Folklore, Chicago, Argonaut Publishers, 1969, б. 3. 


\section{9. $T \alpha v \pi o \delta \eta \dot{\eta} \alpha \tau \alpha$}

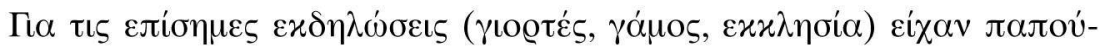

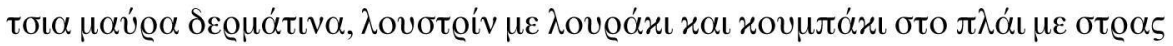

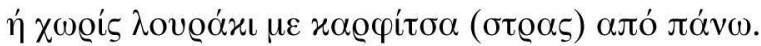

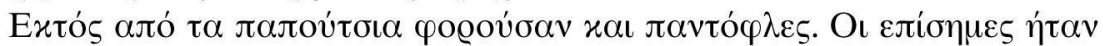

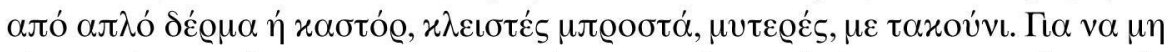

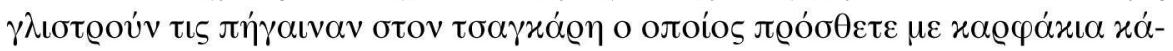

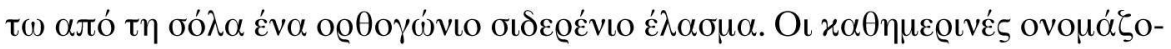

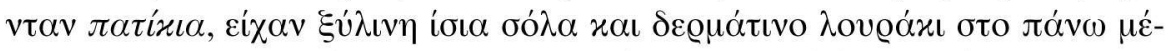

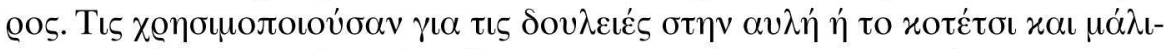

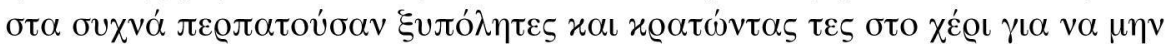

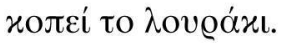

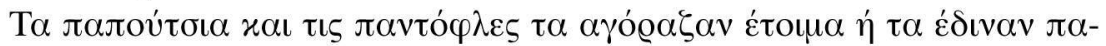

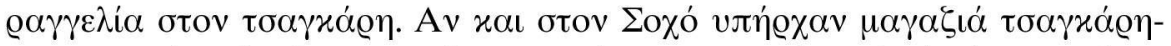

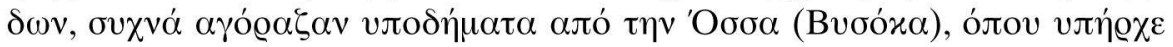

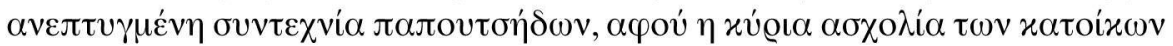

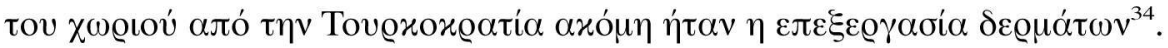

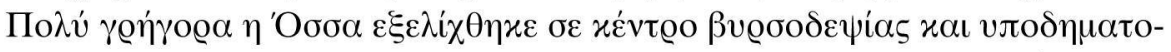

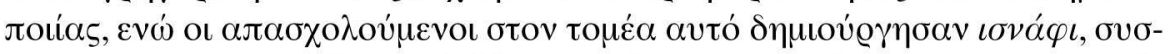

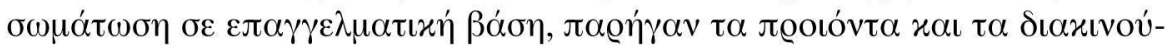

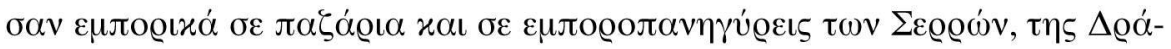

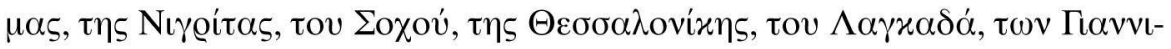

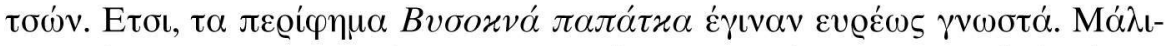

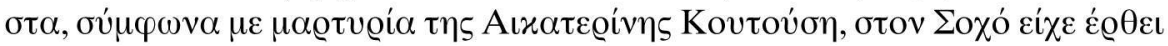

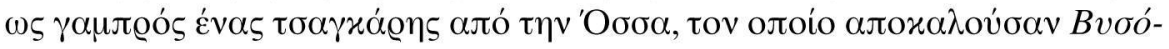

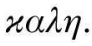

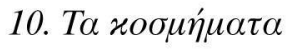

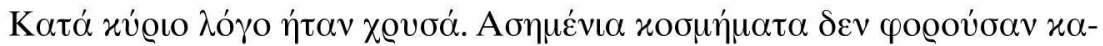

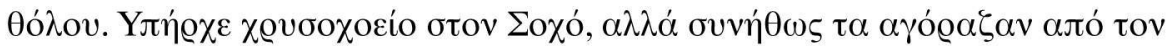

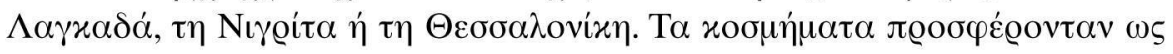

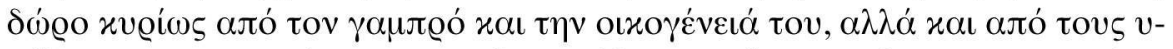

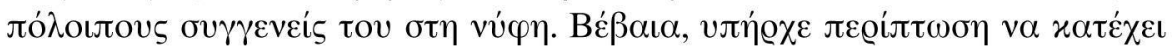
$\mu \iota \alpha$ oњ

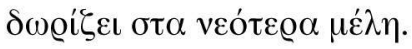

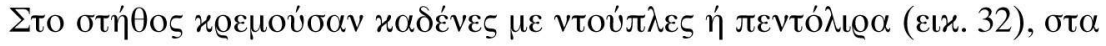

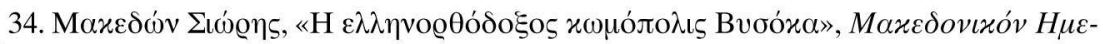

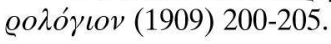




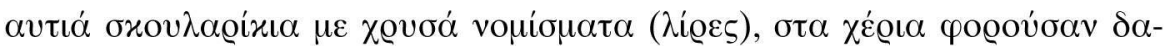

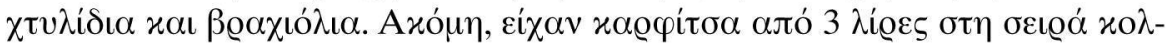

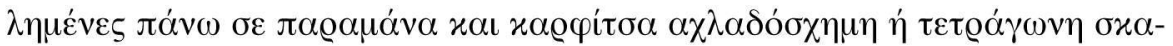

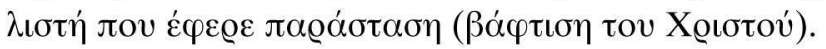

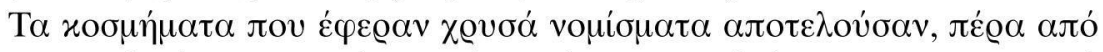

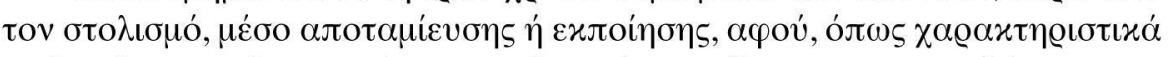

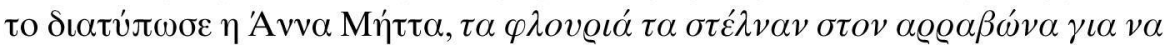

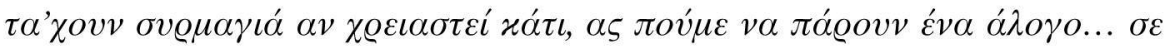

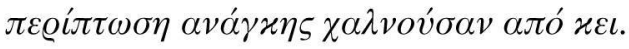

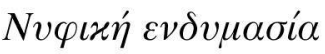

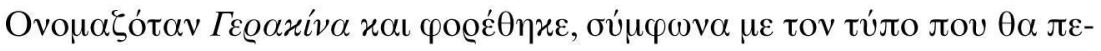

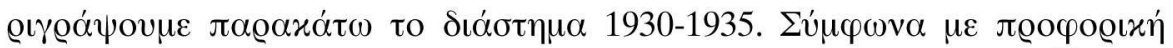

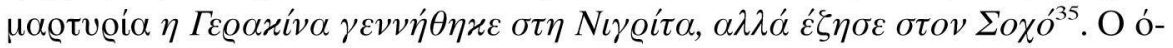

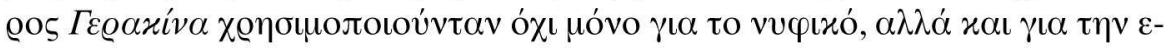

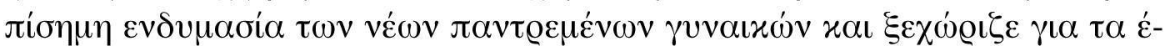

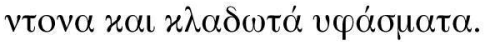

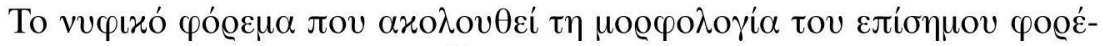

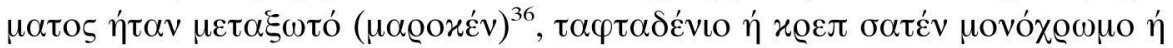

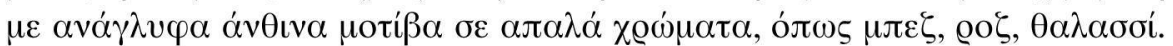

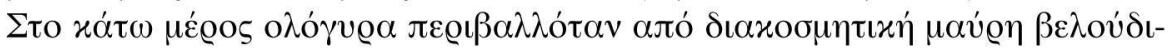

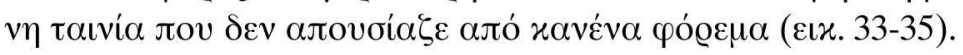

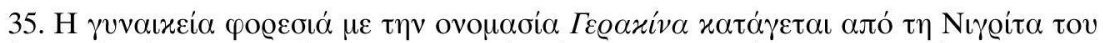

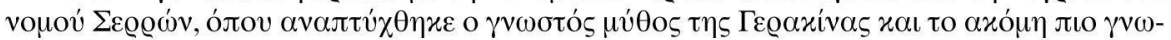

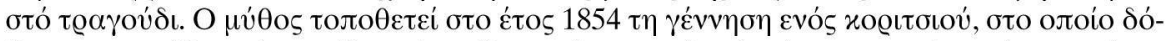

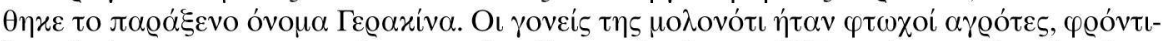

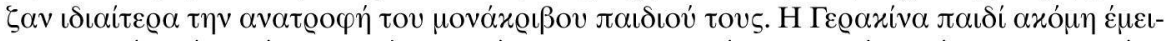

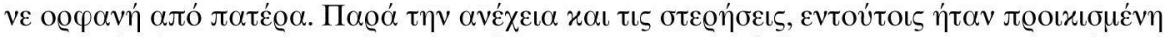

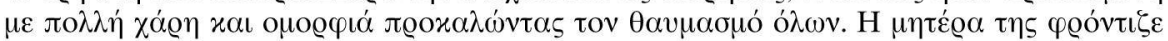

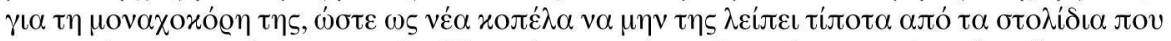

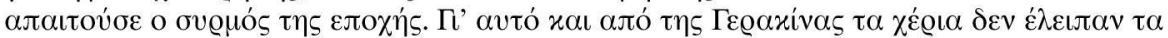

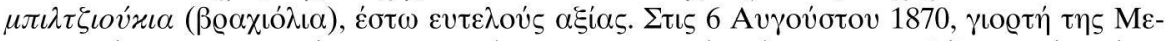

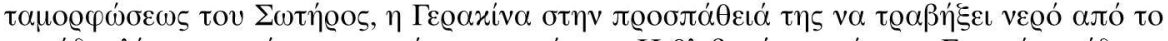

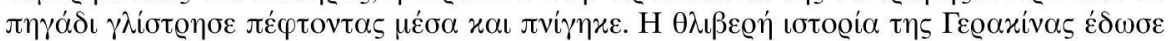

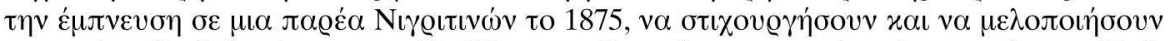

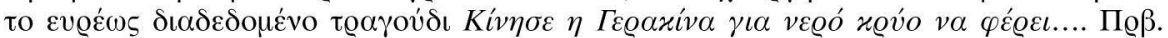

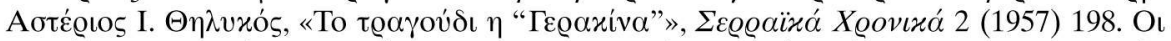

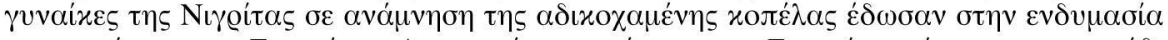

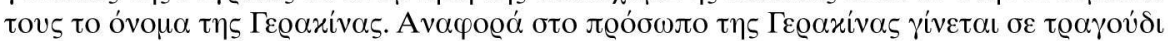

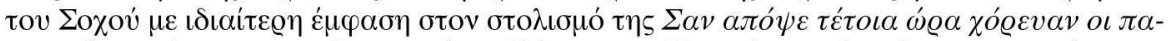

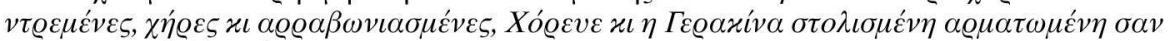

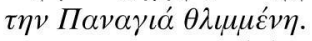

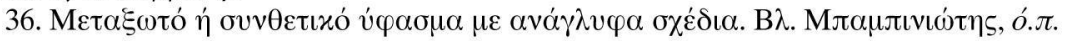




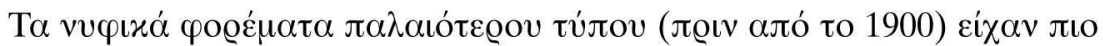

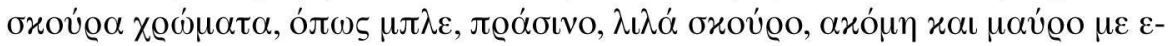

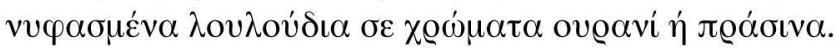

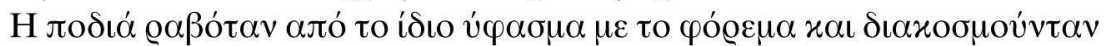

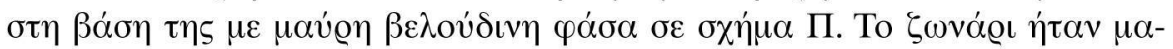

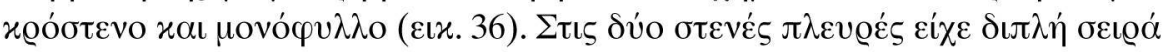

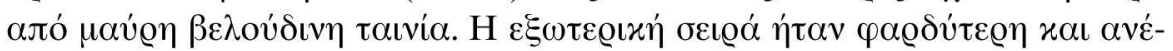

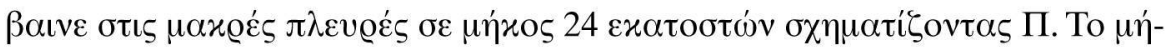

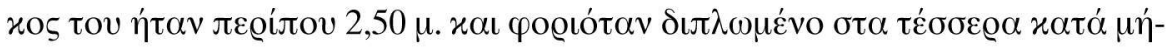
xos.

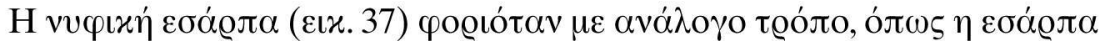

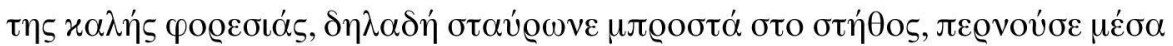

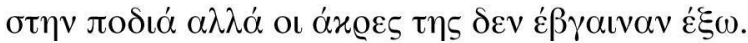

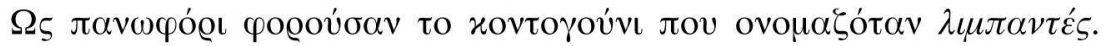

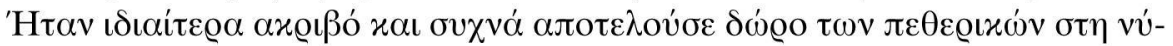

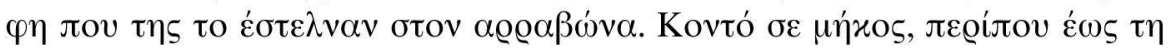

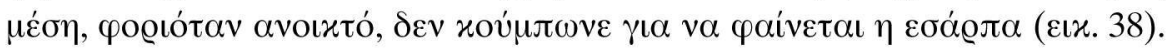

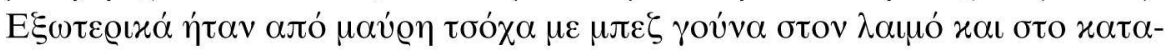

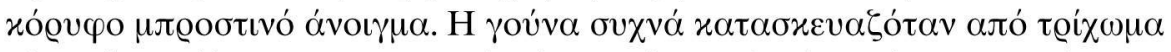

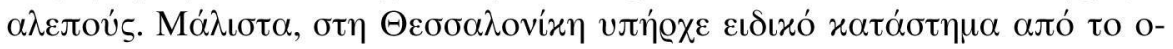

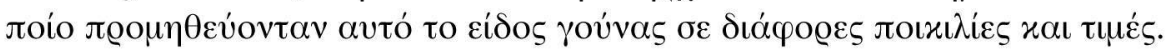

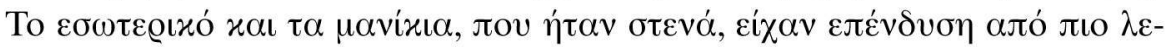

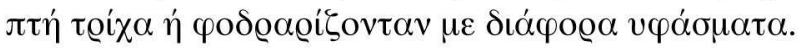

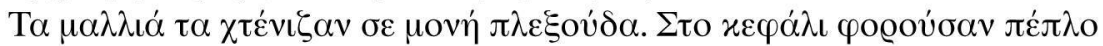

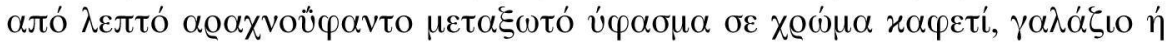

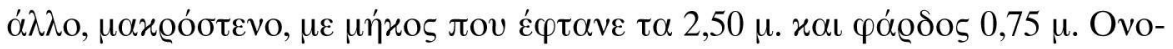

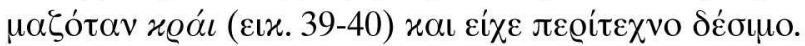

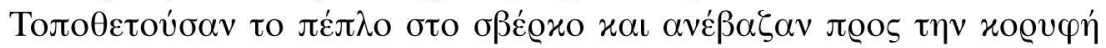

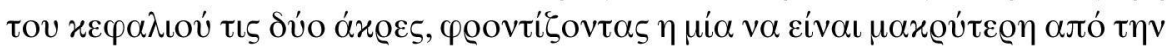

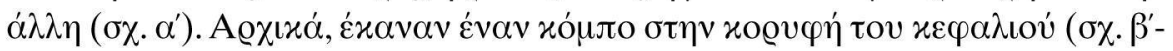

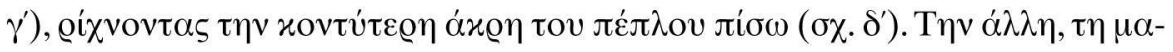

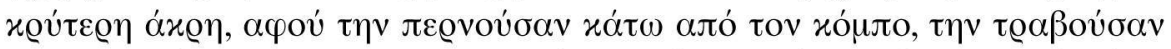

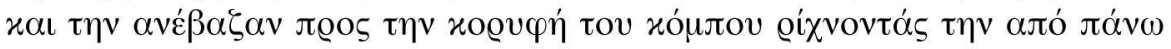

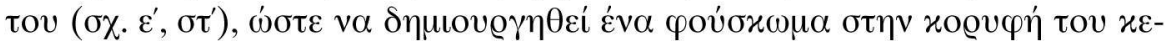

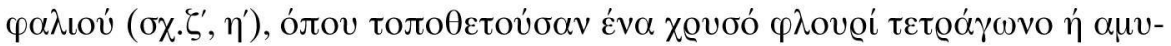

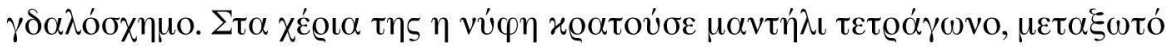

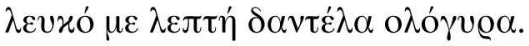

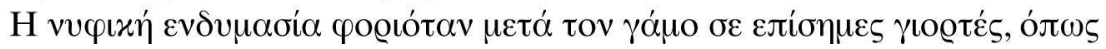

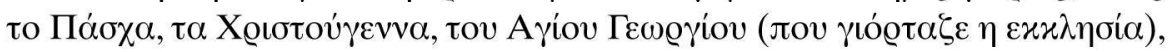

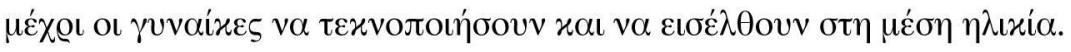




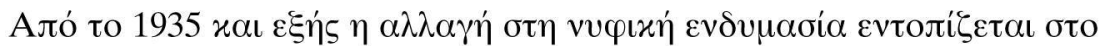

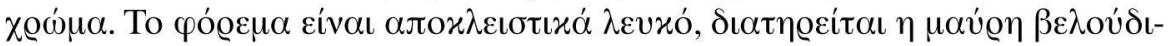

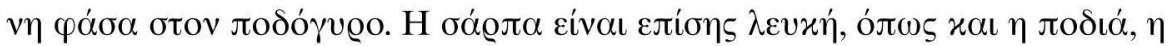

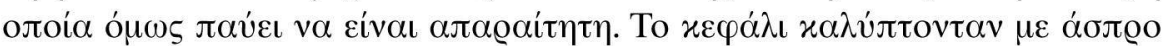

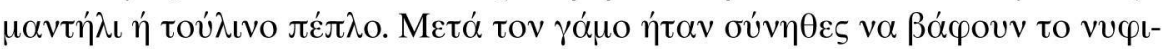

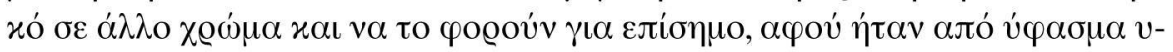

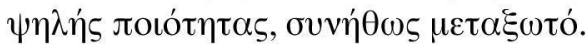

\section{$\Gamma \Lambda \Omega \Sigma \Sigma$ API}

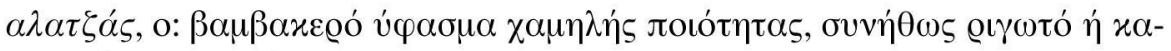
@ó $<$ tov @x. alaca.

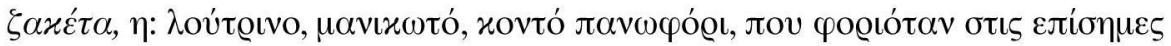

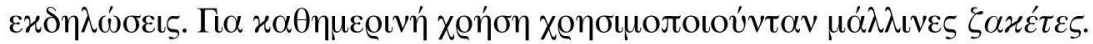

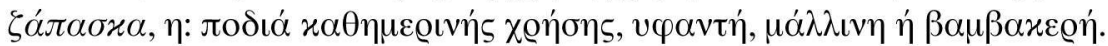

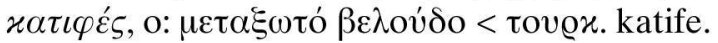

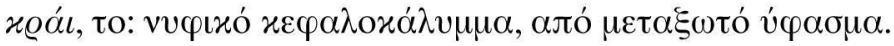

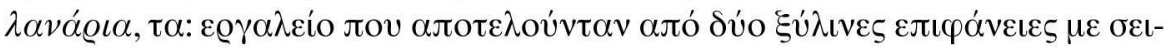

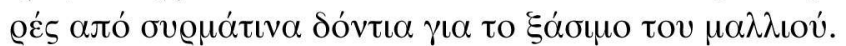

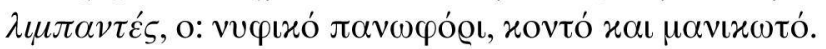

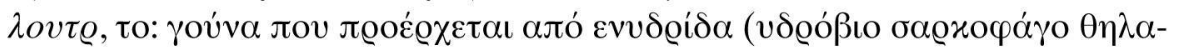

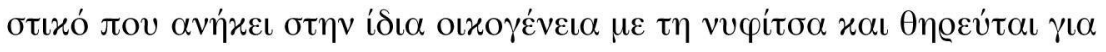

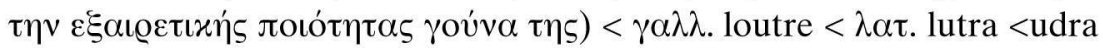

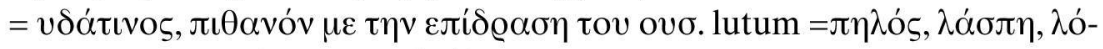

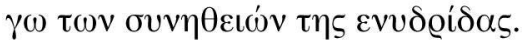

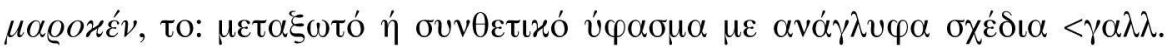
maroquin $<$ Maroc $=$ M $\alpha$ @óxo.

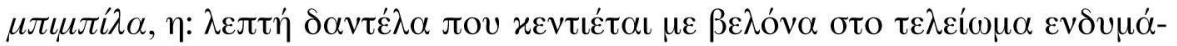

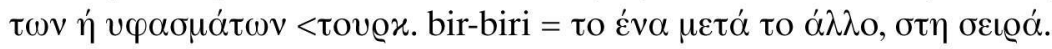

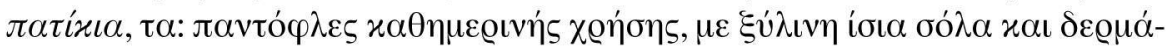

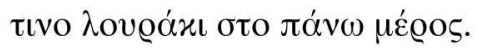

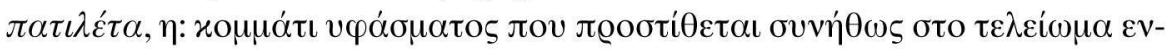

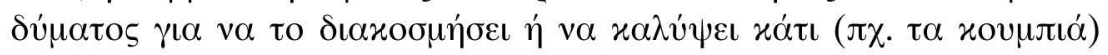

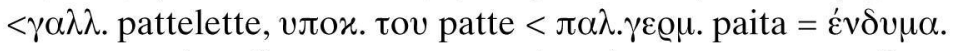

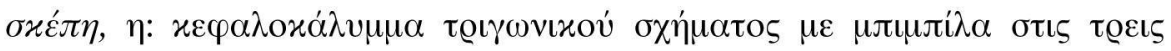

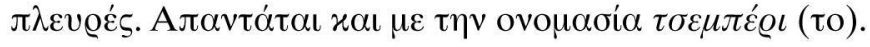

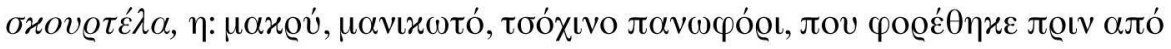
тo 1920.

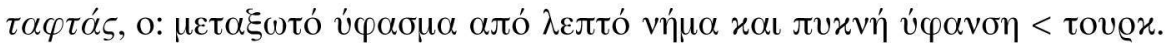
tafta. 


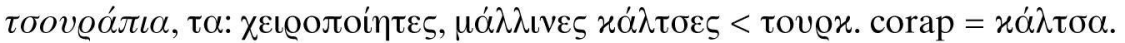

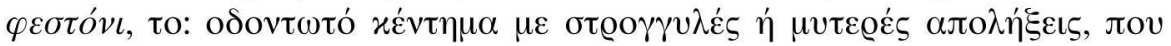

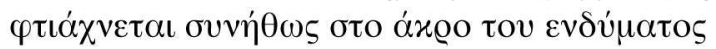

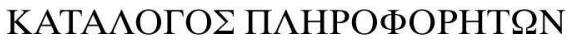

ONOMATEП $\Omega N Y M O$

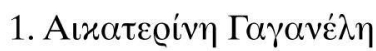

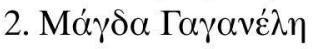

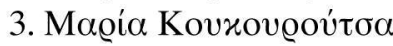

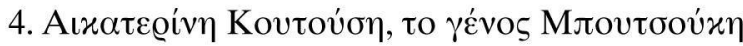

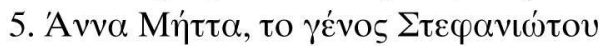

6. 'A $\gamma \gamma \varepsilon \lambda \circ \mathrm{s}_{\mathrm{S}} \mathrm{M} \tau \tau \alpha \varsigma \mathrm{s}$

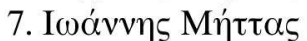

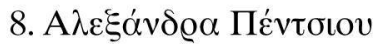

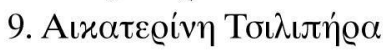

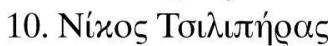

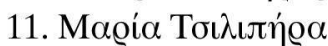

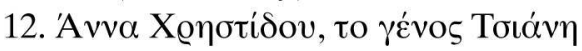

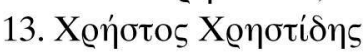

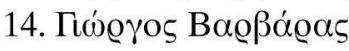

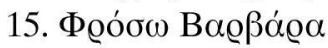

\begin{tabular}{|c|c|}
\hline 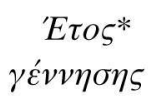 & 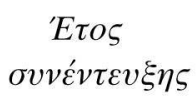 \\
\hline \multirow[t]{2}{*}{1918} & 2003 \\
\hline & 2003 \\
\hline 1912 & 2003 \\
\hline 1932 & 2003,2005 \\
\hline 1936 & 2005 \\
\hline 1931 & 2005 \\
\hline 1962 & 2005 \\
\hline 1922 & 2003 \\
\hline \multirow[t]{3}{*}{1919} & 2004 \\
\hline & 2004 \\
\hline & 2004 \\
\hline 1956 & 2003 \\
\hline 1948 & 2003 \\
\hline 1976 & 2003 \\
\hline 1977 & 2003 \\
\hline
\end{tabular}

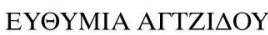

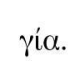

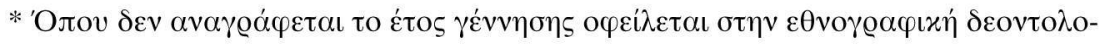




\section{SUMMARY}

Efthimia Agtzidou, The traditional female costume of Sochos (Thessaloniki).

The study concerns the traditional female costume of Sochos, a village on the borders of the Thessaloniki and Serres prefectures. The majority of the inhabitans of Sochos were natives, while the minority were refugees from the Pontos region, as well as a few Vlach families. The inhabitans dealt with livestock breeding, agriculture and trade. They got along well with the inhabitants of Ossa, a village near the town of Lagadas, and mostly with the inhabitants of Nigrita, a village in the Serres prefecture with which they shared similarities in customs, traditions and costumes.

The study was based on field work carried out in Sochos and in the city of Thessaloniki, where a large group of inhabitants of Sochos settled down in the 60 's and 70's. The goal of this study was to record the female costume of Sochos, as it is a subject lacking bibliography citations.

The female costume, as described, was worn from 1920 up to 1970. The study is divided in two units. In the first unit the main parts of the costume are thoroughly described, in the sequence they were put on, starting with the underwear and reaching even jewelry. Moreover, in the cases where enough proof could be gathered, parts of the female costume of older times are presented (before 1920).

The second unit refers to the bridal costume, known as «Gerakina». It was worn according to the type described up to 1930/5. The bridal costume's parts are analyzed in every possible detail and the changes that have taken place after 1935 are located. 


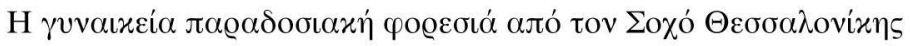

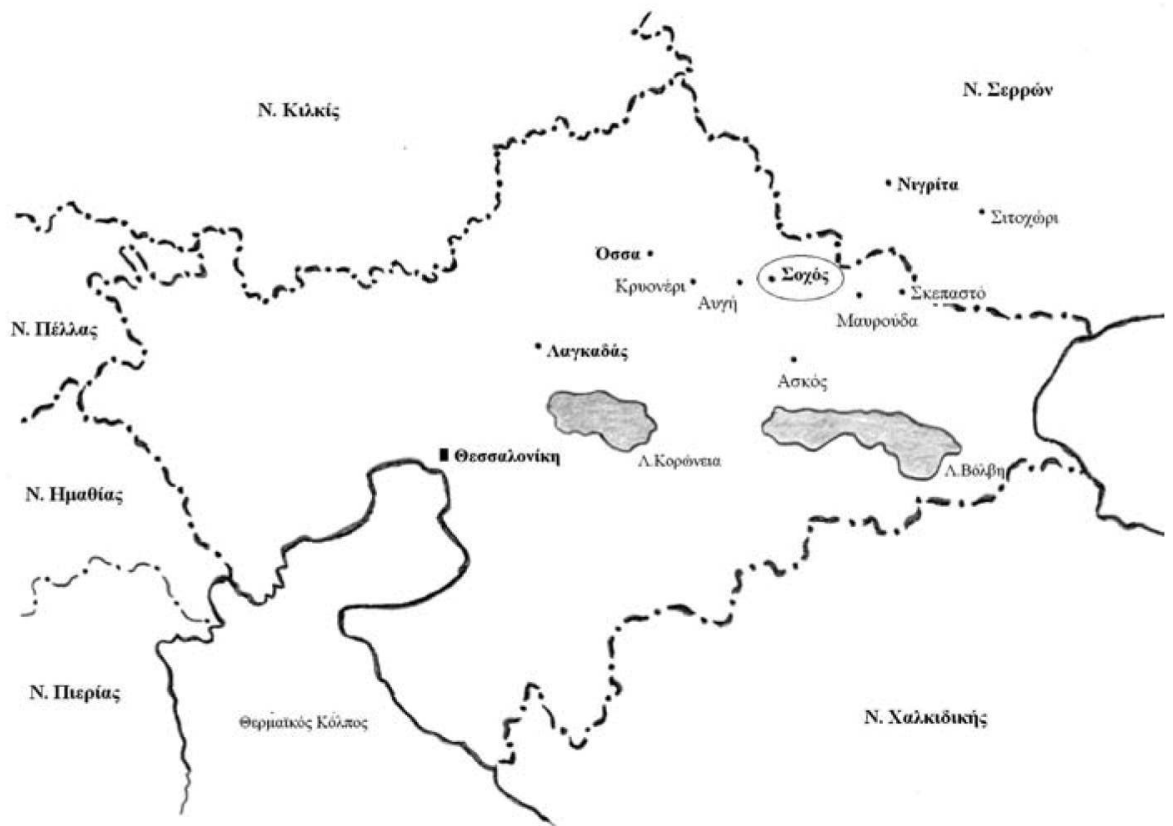

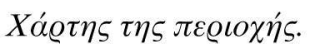

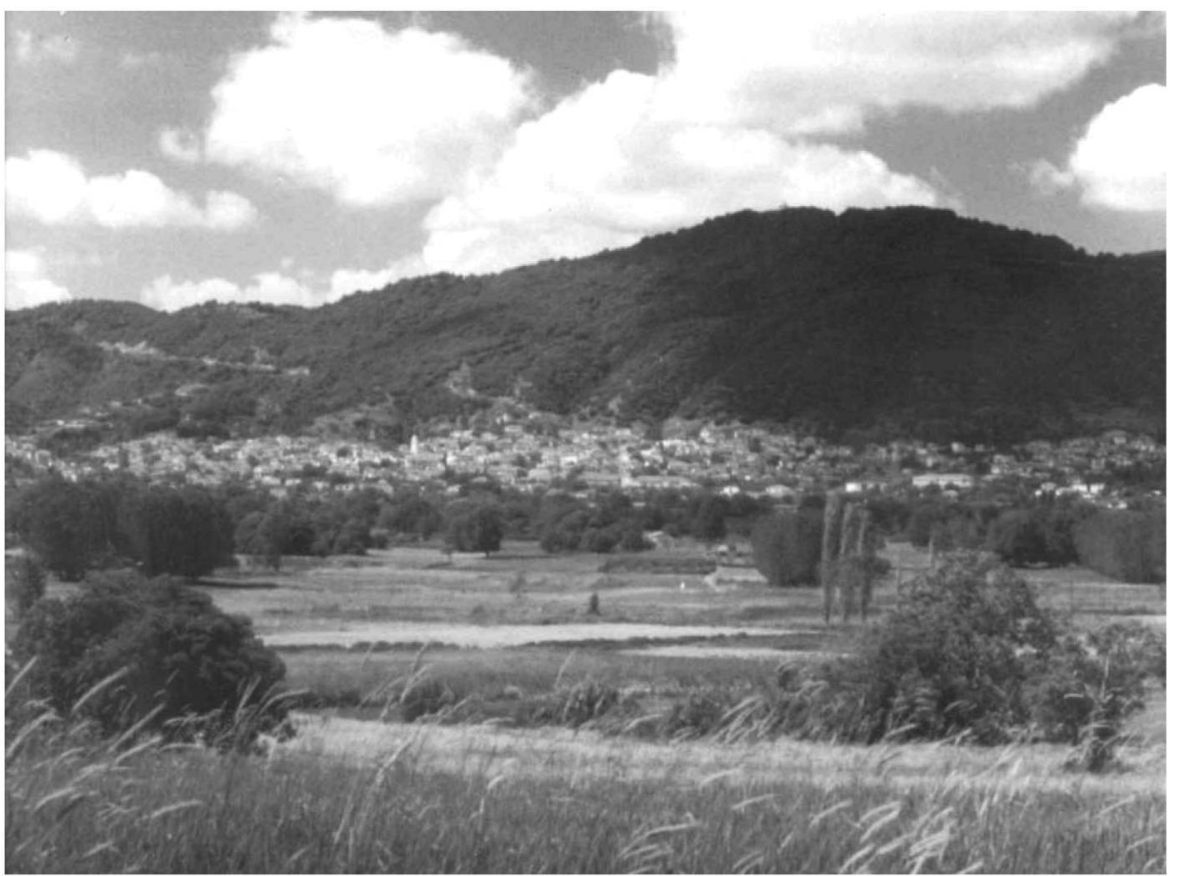

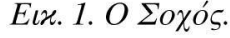




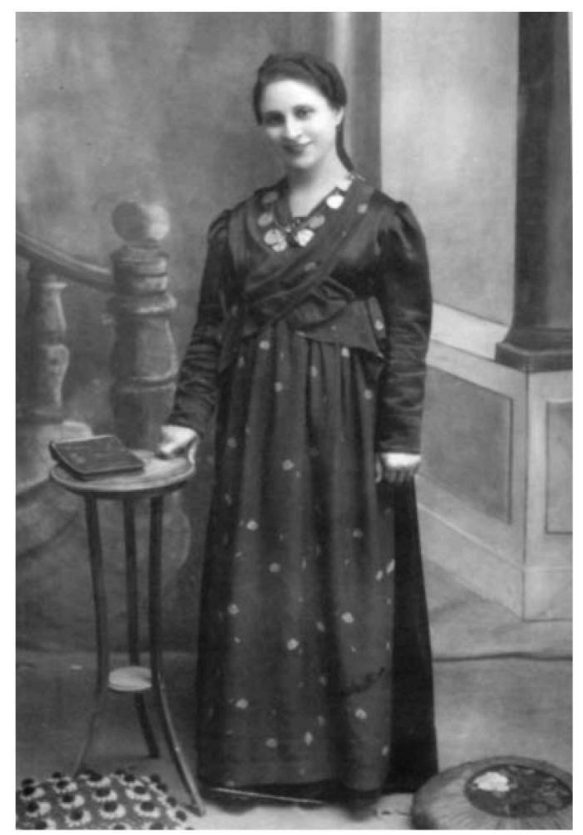

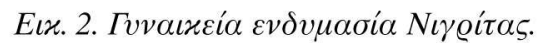

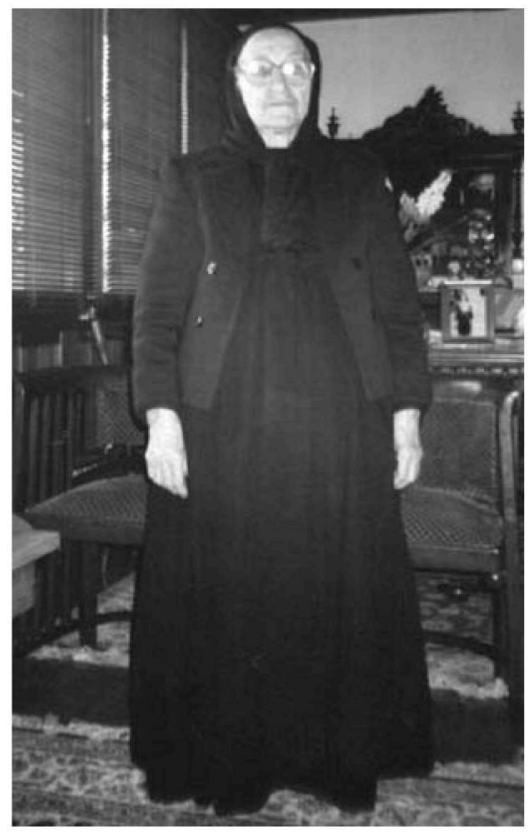

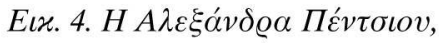

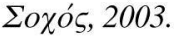

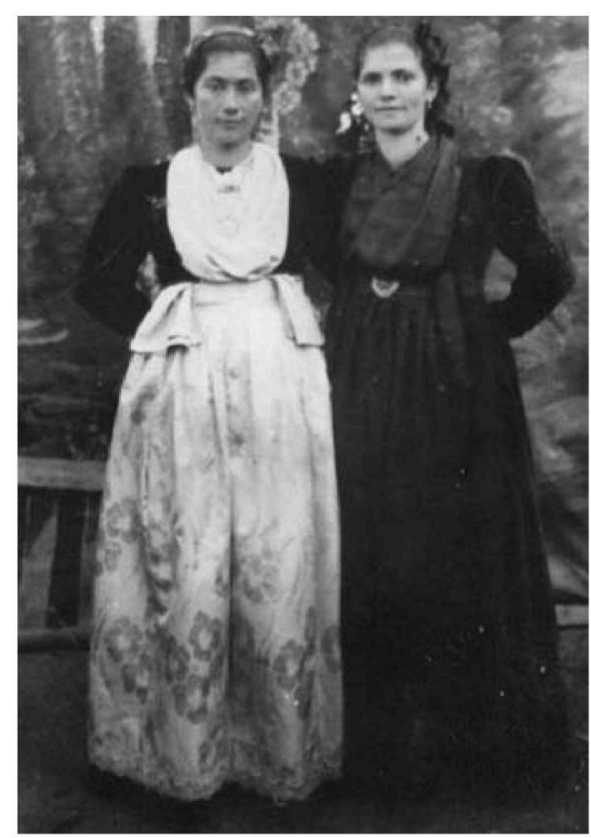

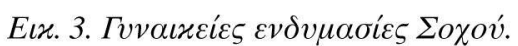

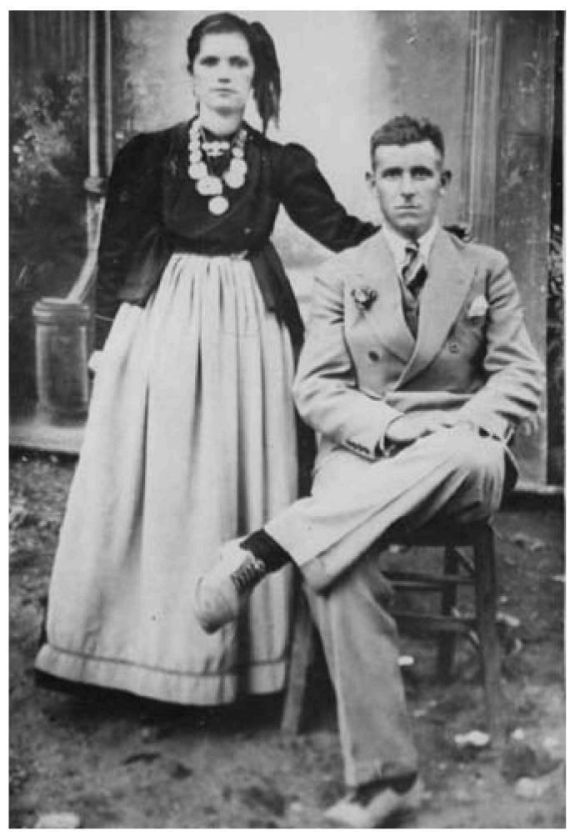

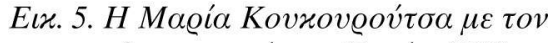

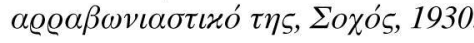




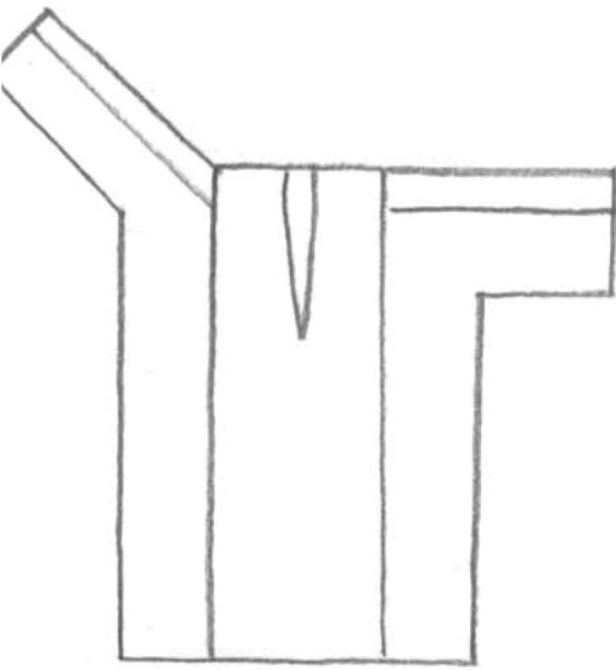

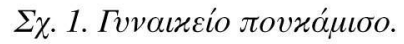

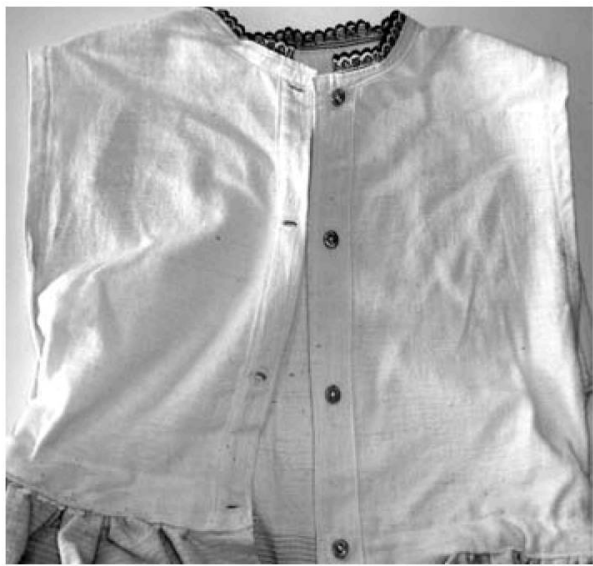

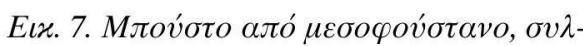

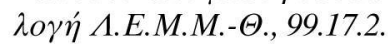

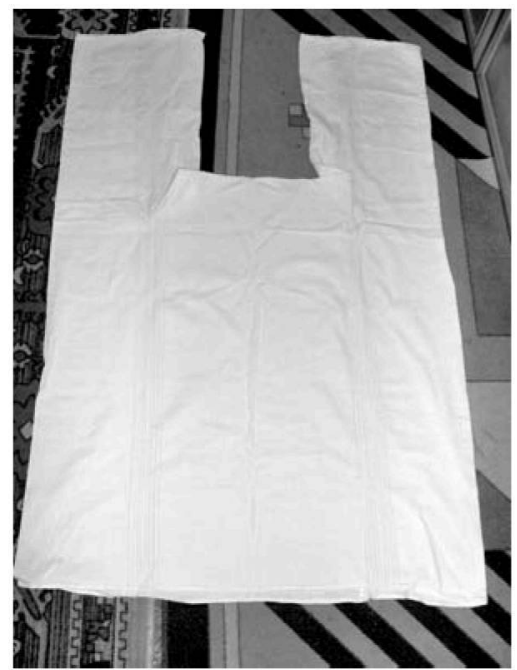

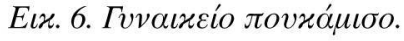

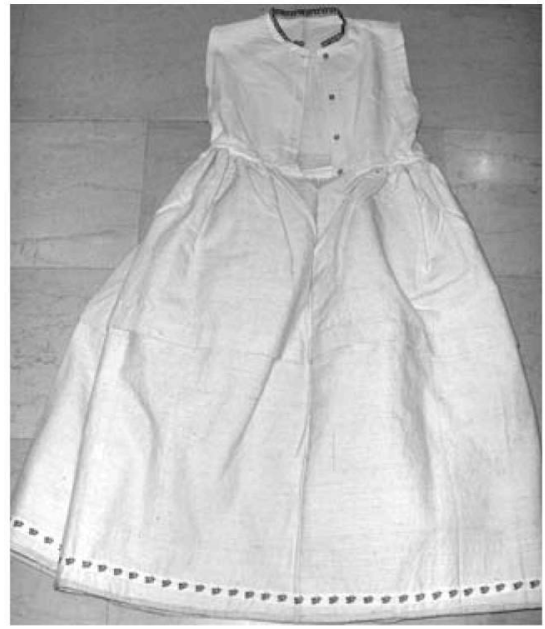

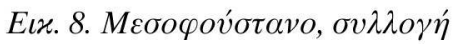

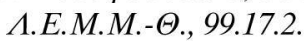




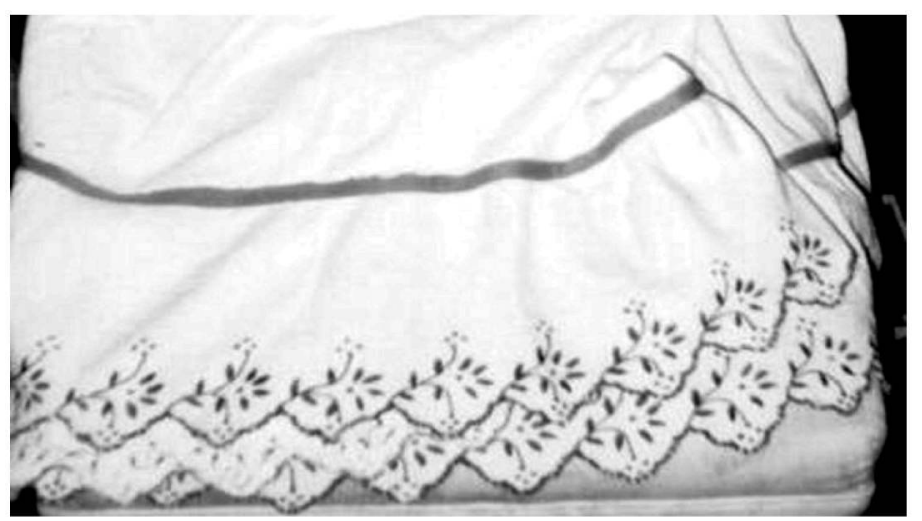

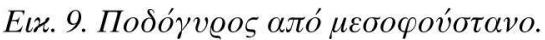

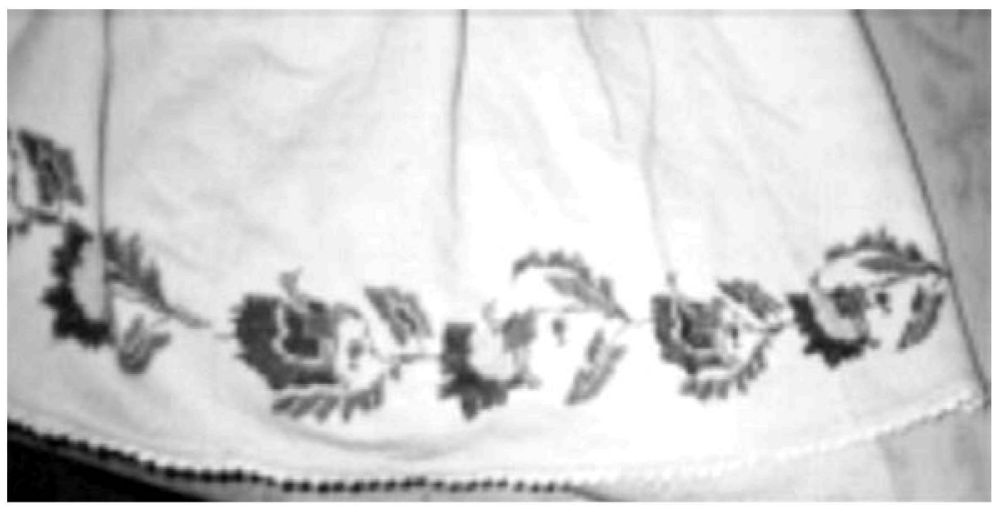

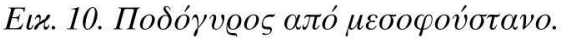

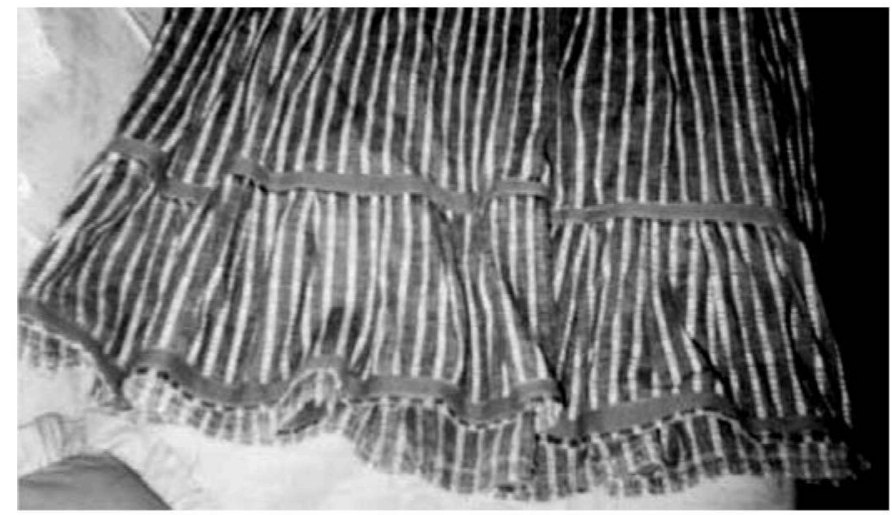

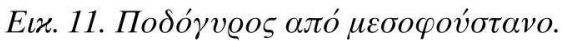




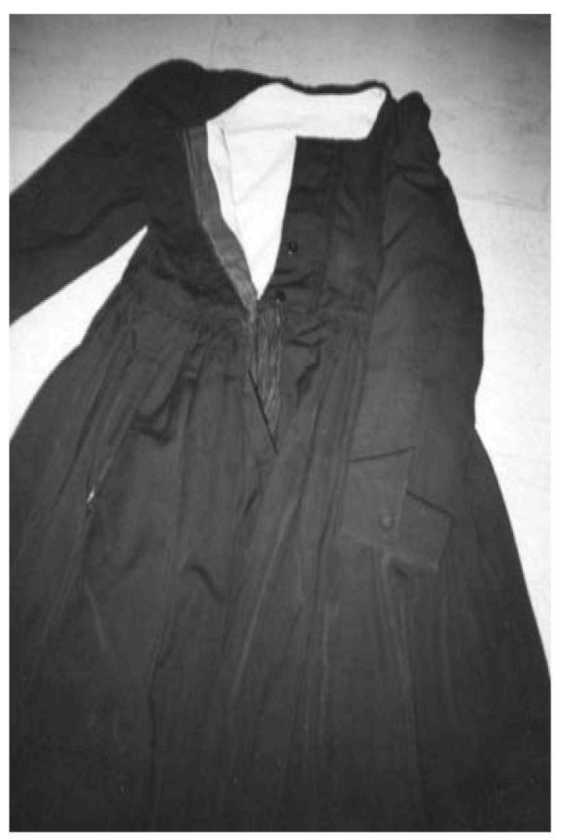

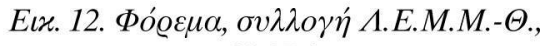
99.17.1.

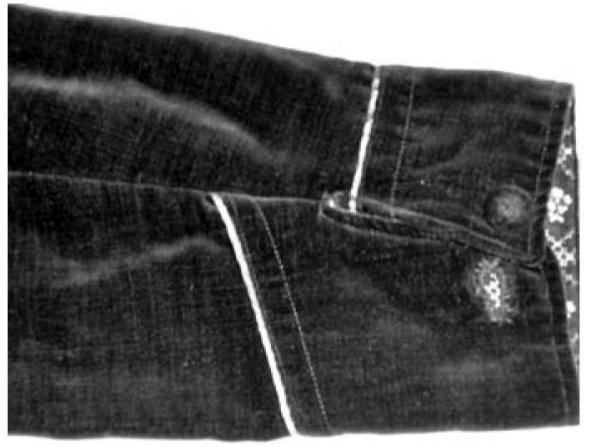

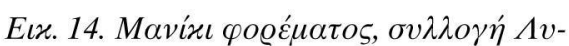

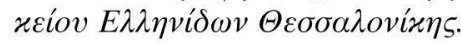

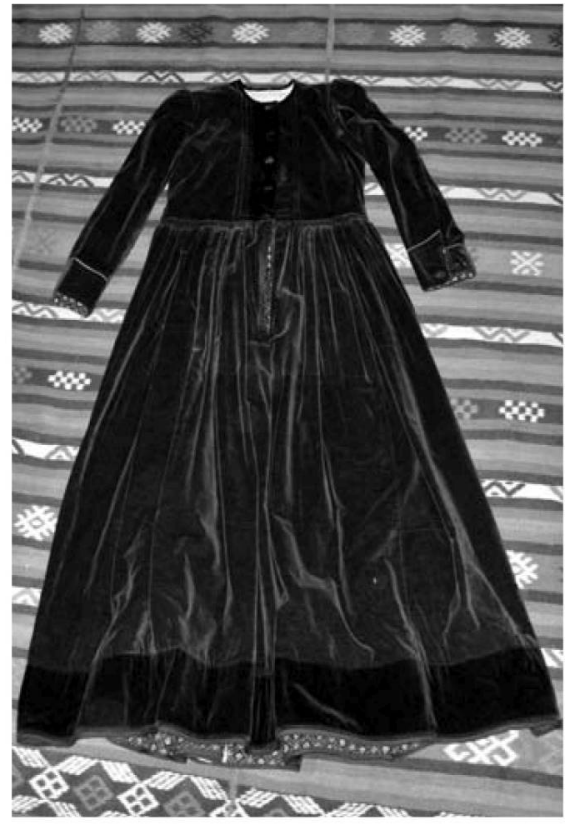

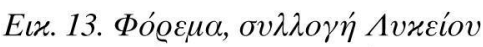

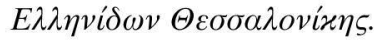

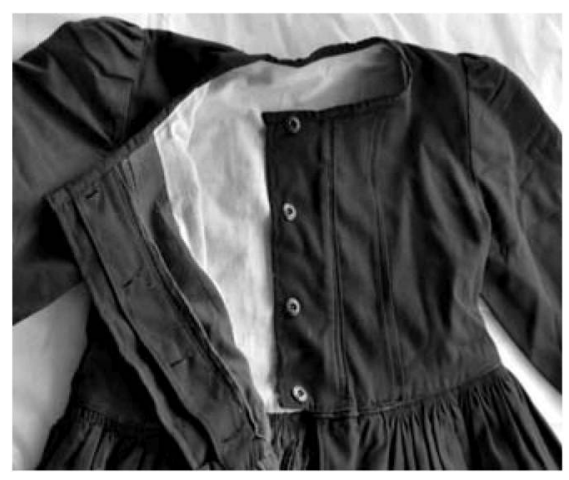

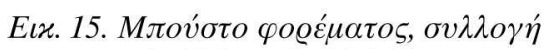

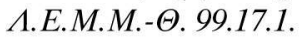




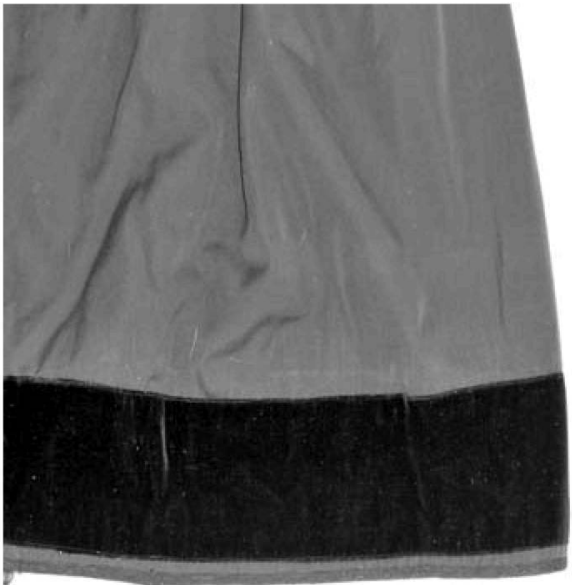

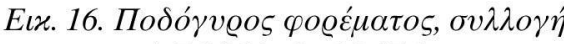

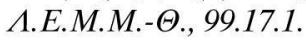

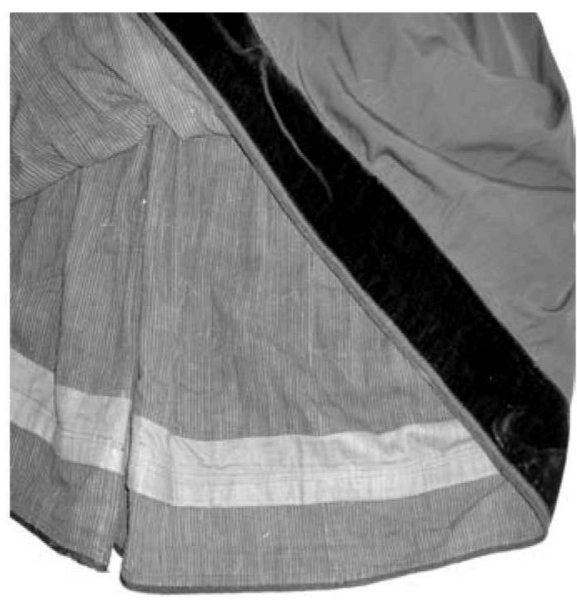

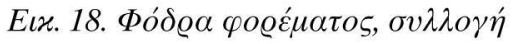

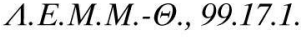

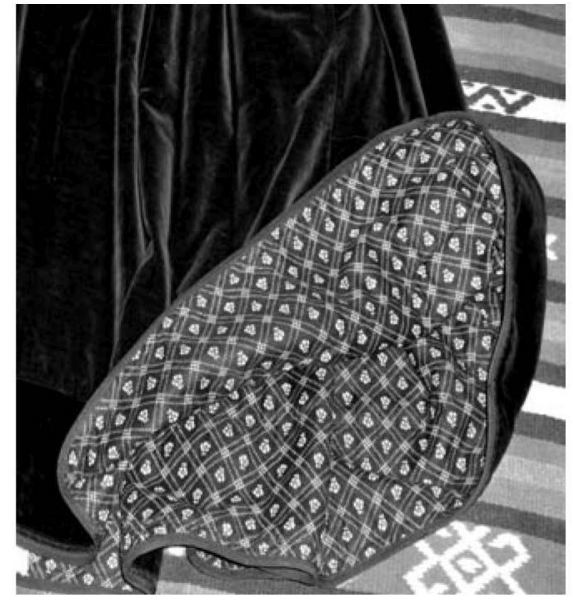

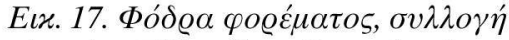

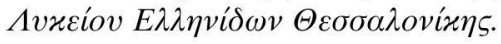

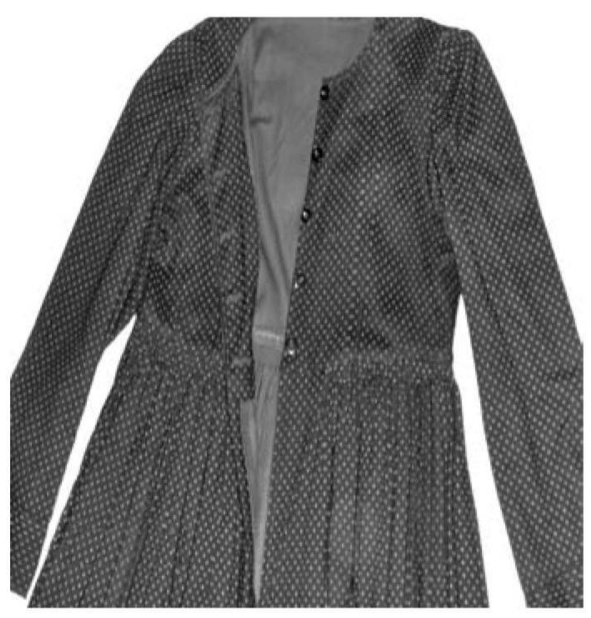

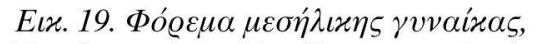

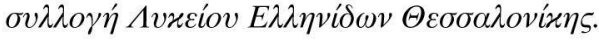




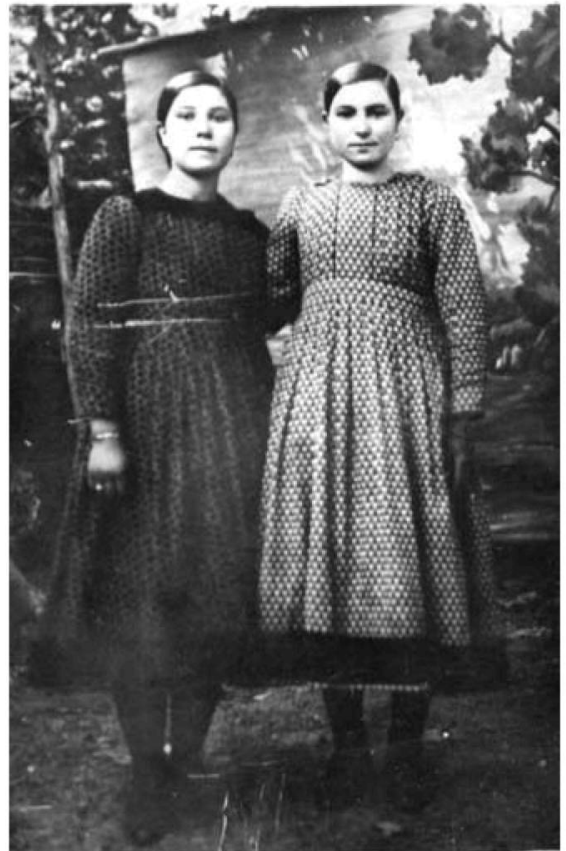

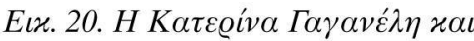

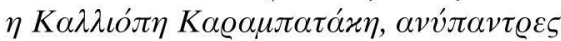

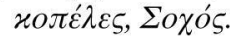

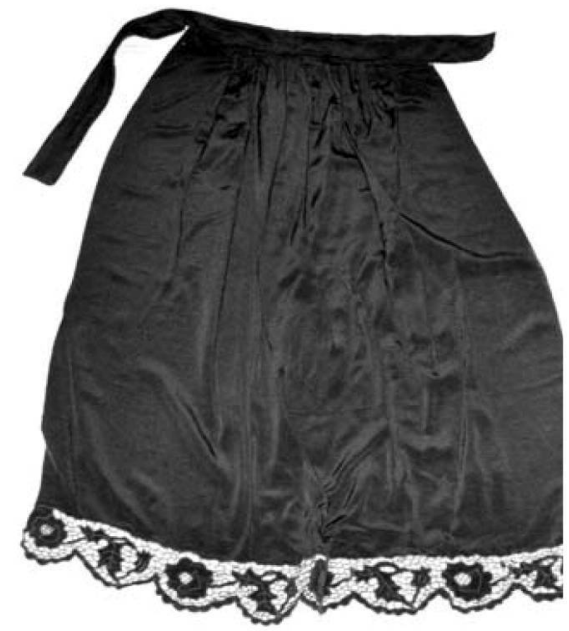

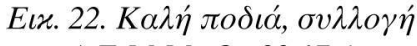
A.E.M.M.- $\Theta ., 99.17 .4$.

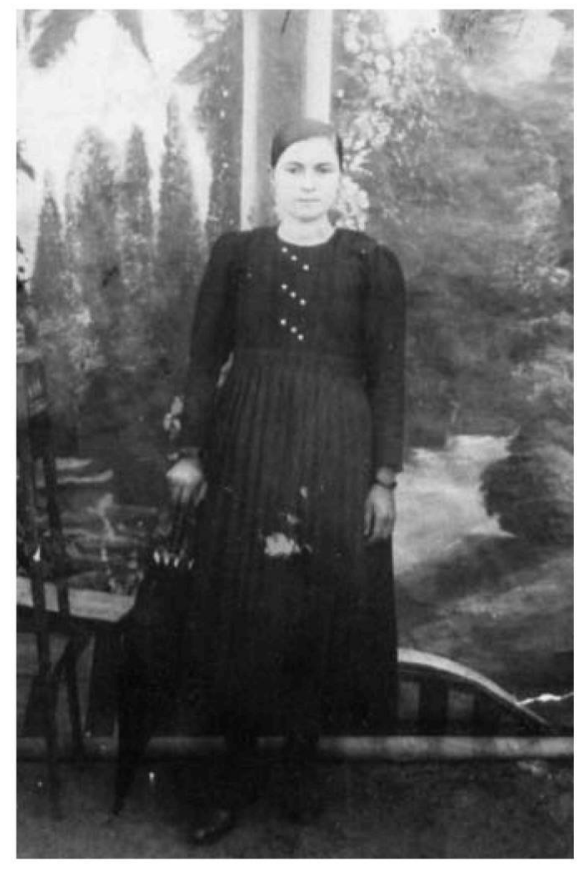

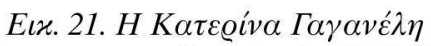

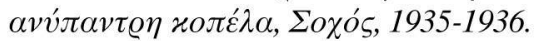

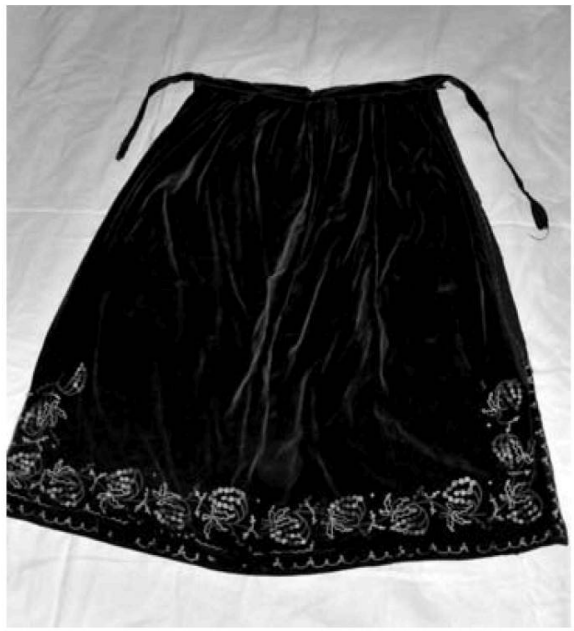

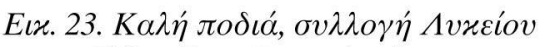

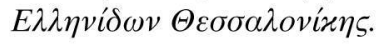




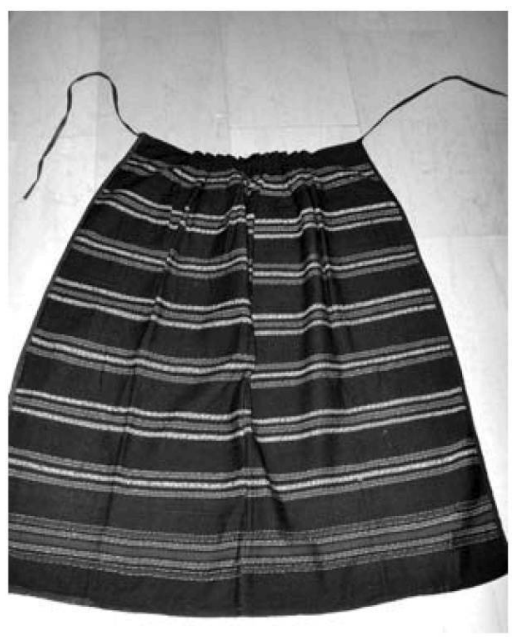

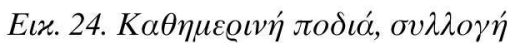

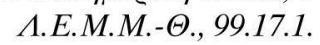

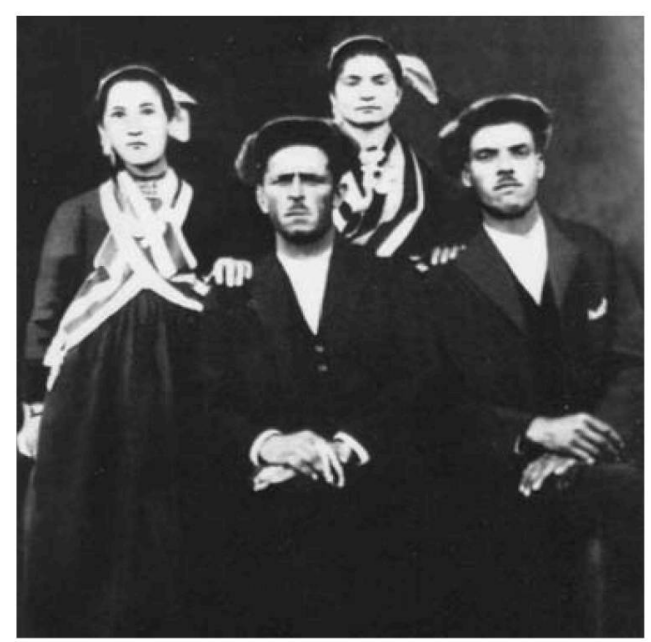

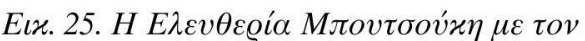
$\alpha \varrho \varrho \alpha \beta \omega v \iota \alpha \sigma \tau \iota x o ́ ~ \tau \eta ऽ ~(\alpha \varrho ı \sigma \tau \varepsilon \varrho \alpha ́) ~ \mu \alpha \zeta i ́ ~ \mu \varepsilon$

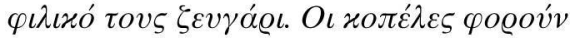

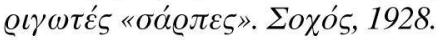

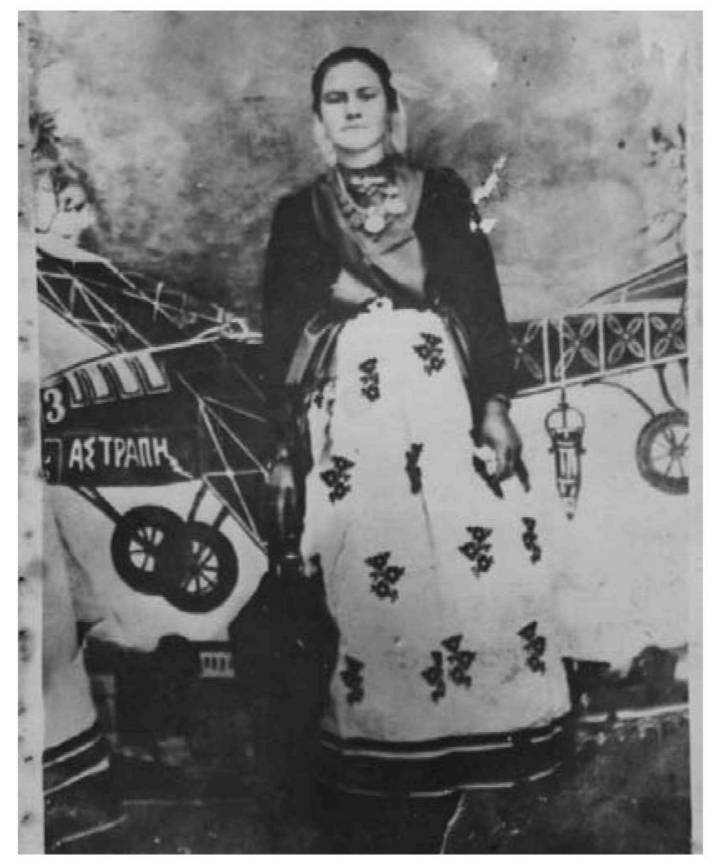

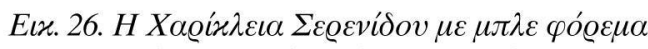

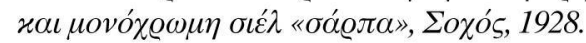




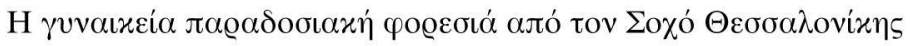

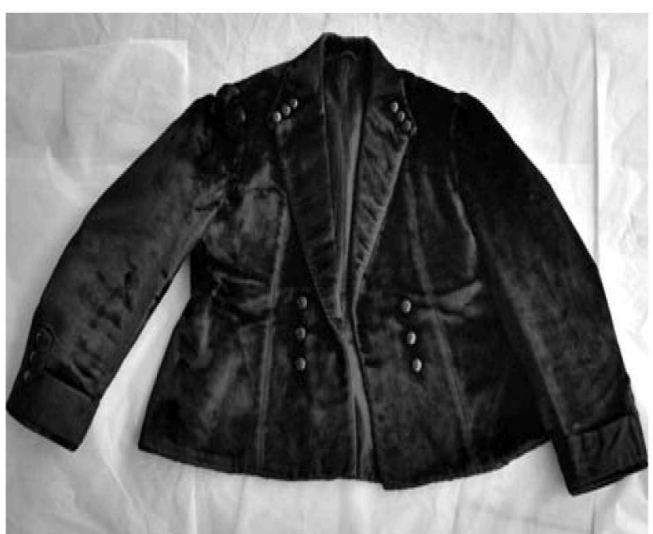

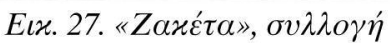
A.E.M.M.- $\Theta$. , 99.17.3.

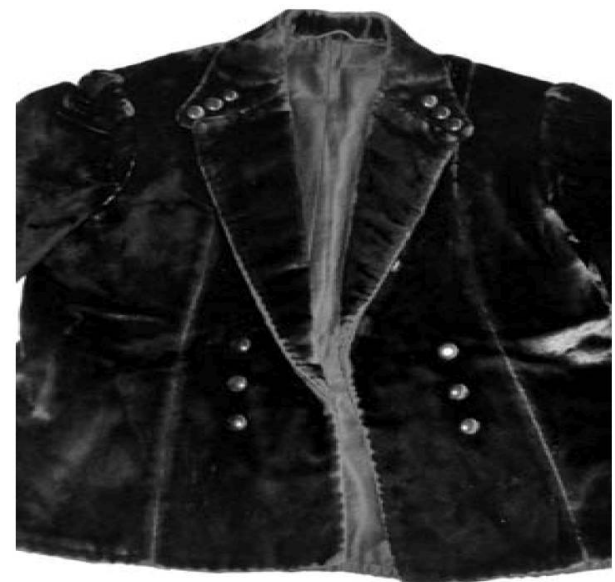

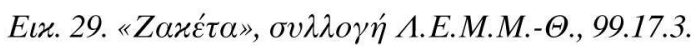

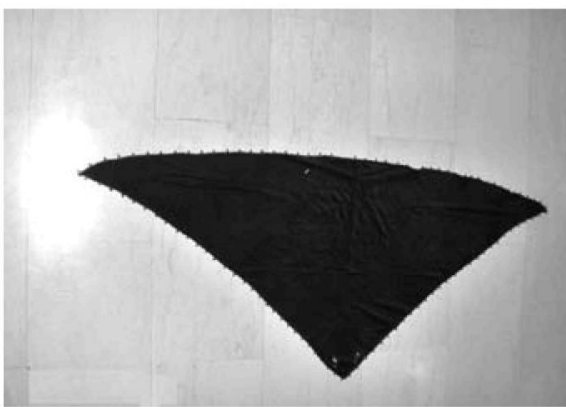

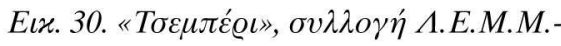
$\Theta .$, 99.17.9.

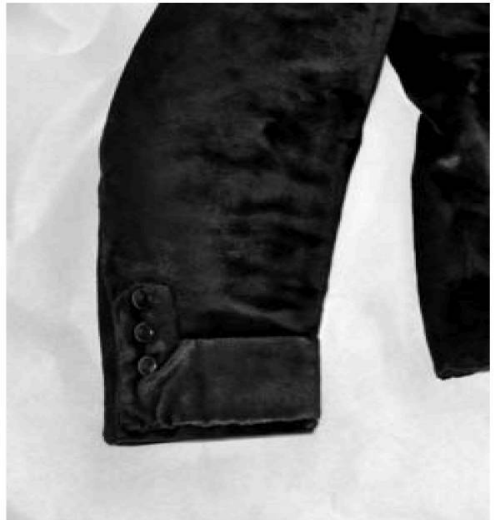

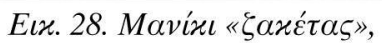

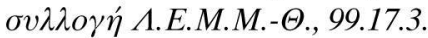

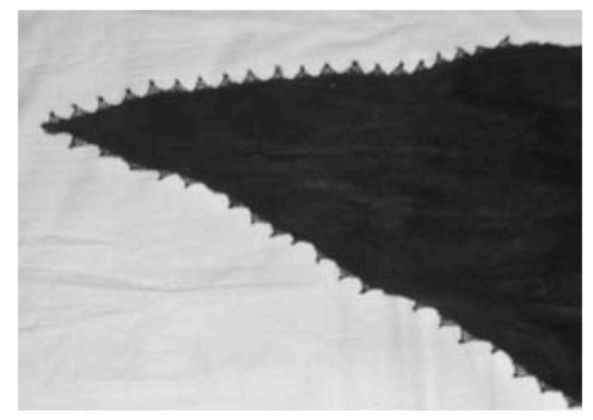

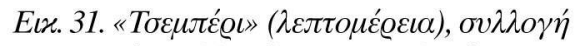

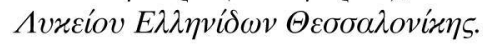




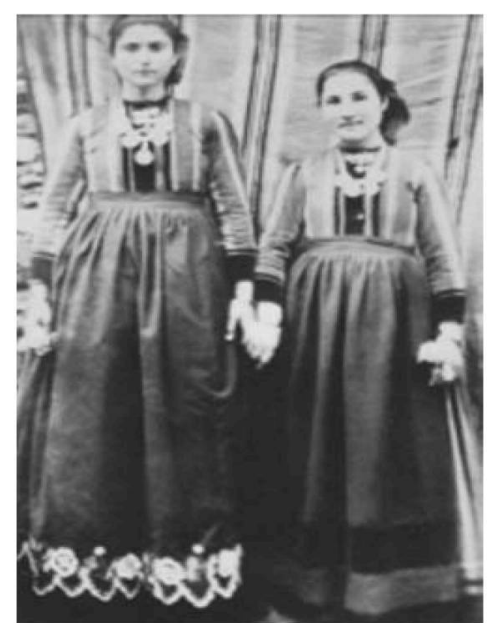

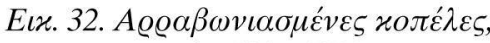

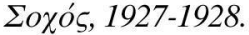

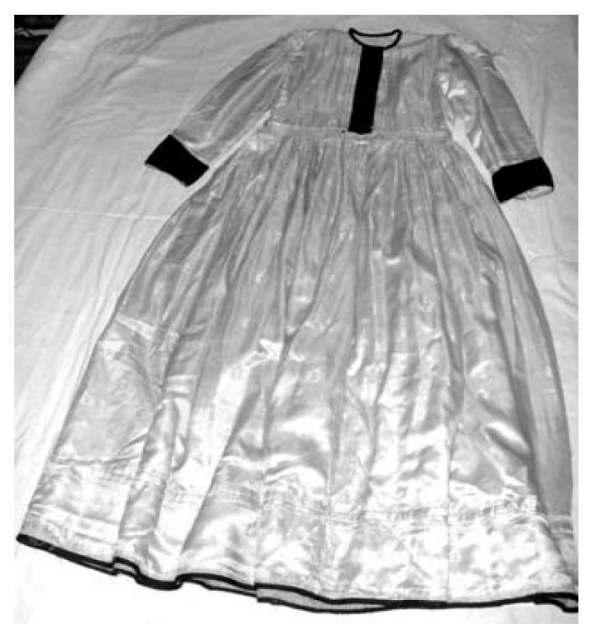

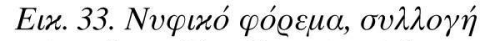

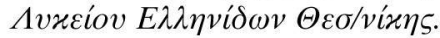

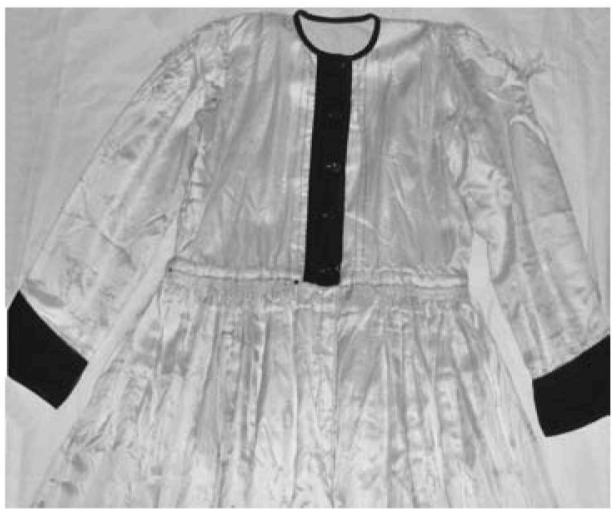

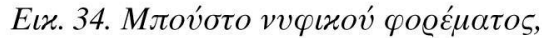

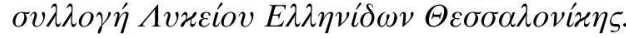

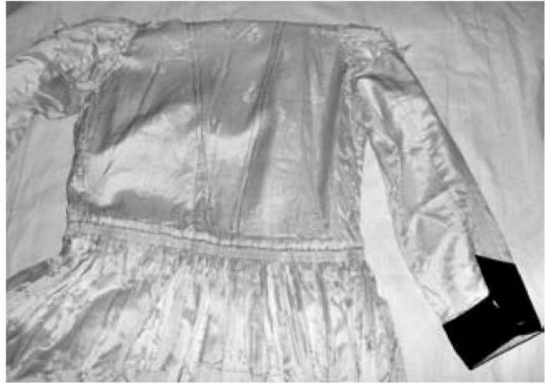

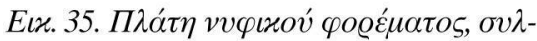

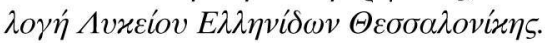

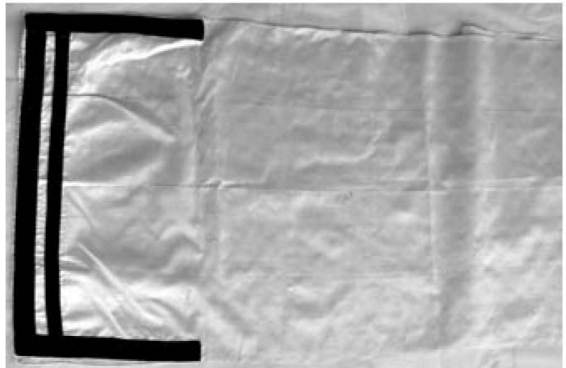

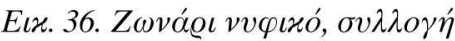
A.E.M.M.- $\Theta ., 99.17 .6$ 


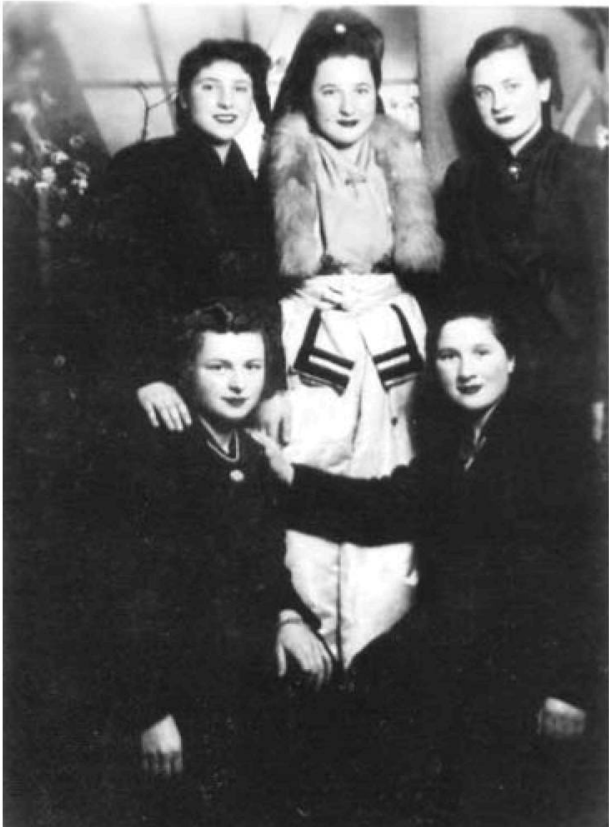

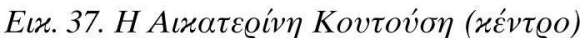

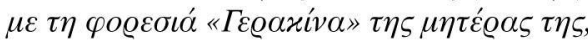
1950.

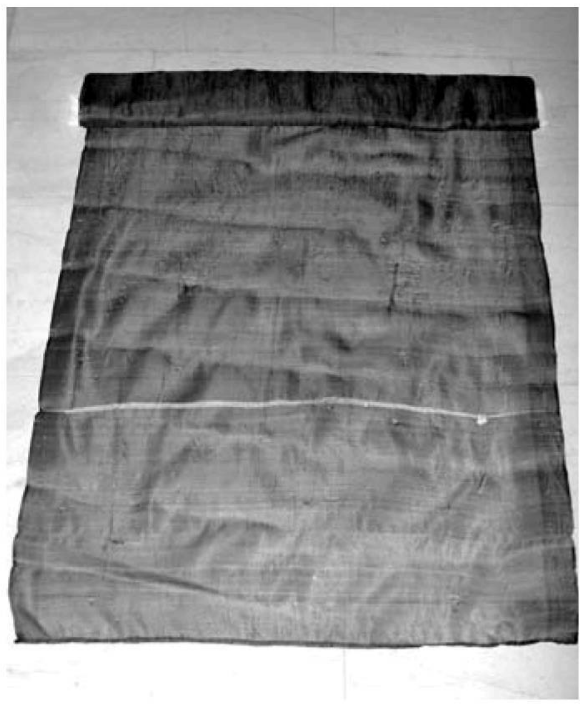

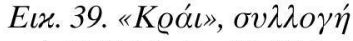
A.E.M.M.- $\Theta ., 99.17 .5$.

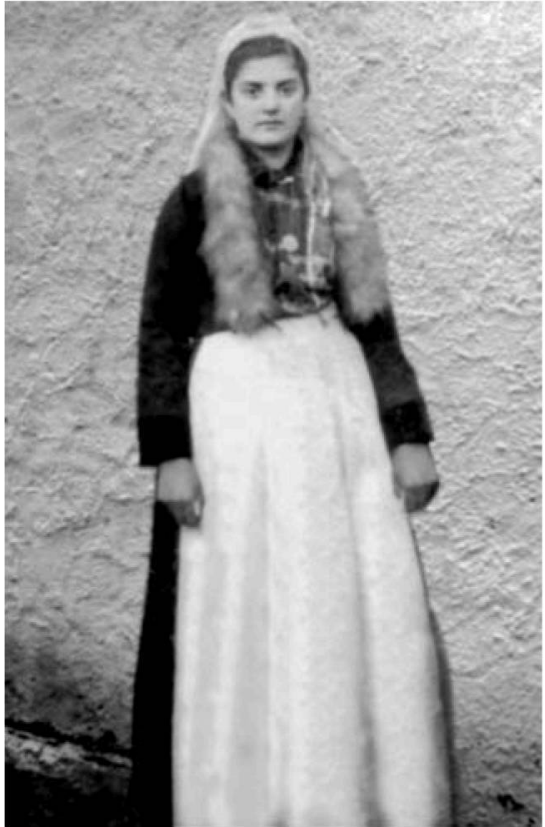

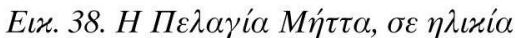

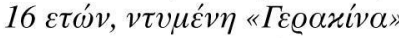
$\mu \varepsilon \ll \lambda \mu \pi \tau \alpha \nu \tau \varepsilon \dot{\varepsilon}$.

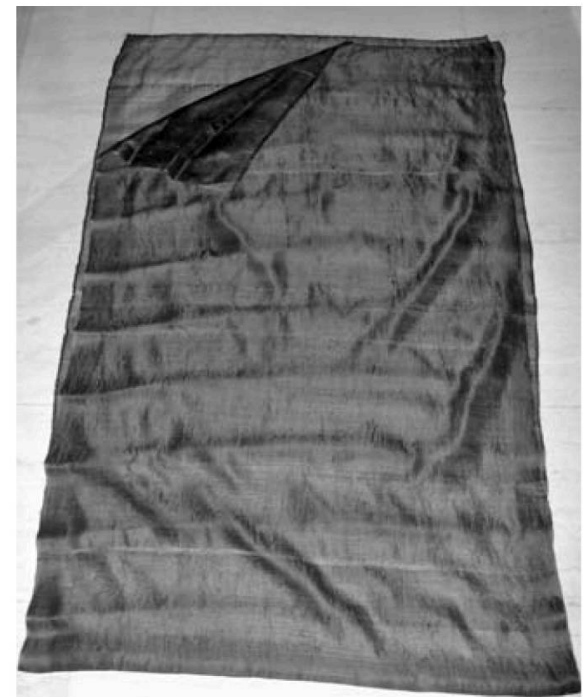

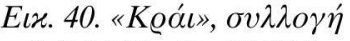
A.E.M.M.-..., 99.17.5. 

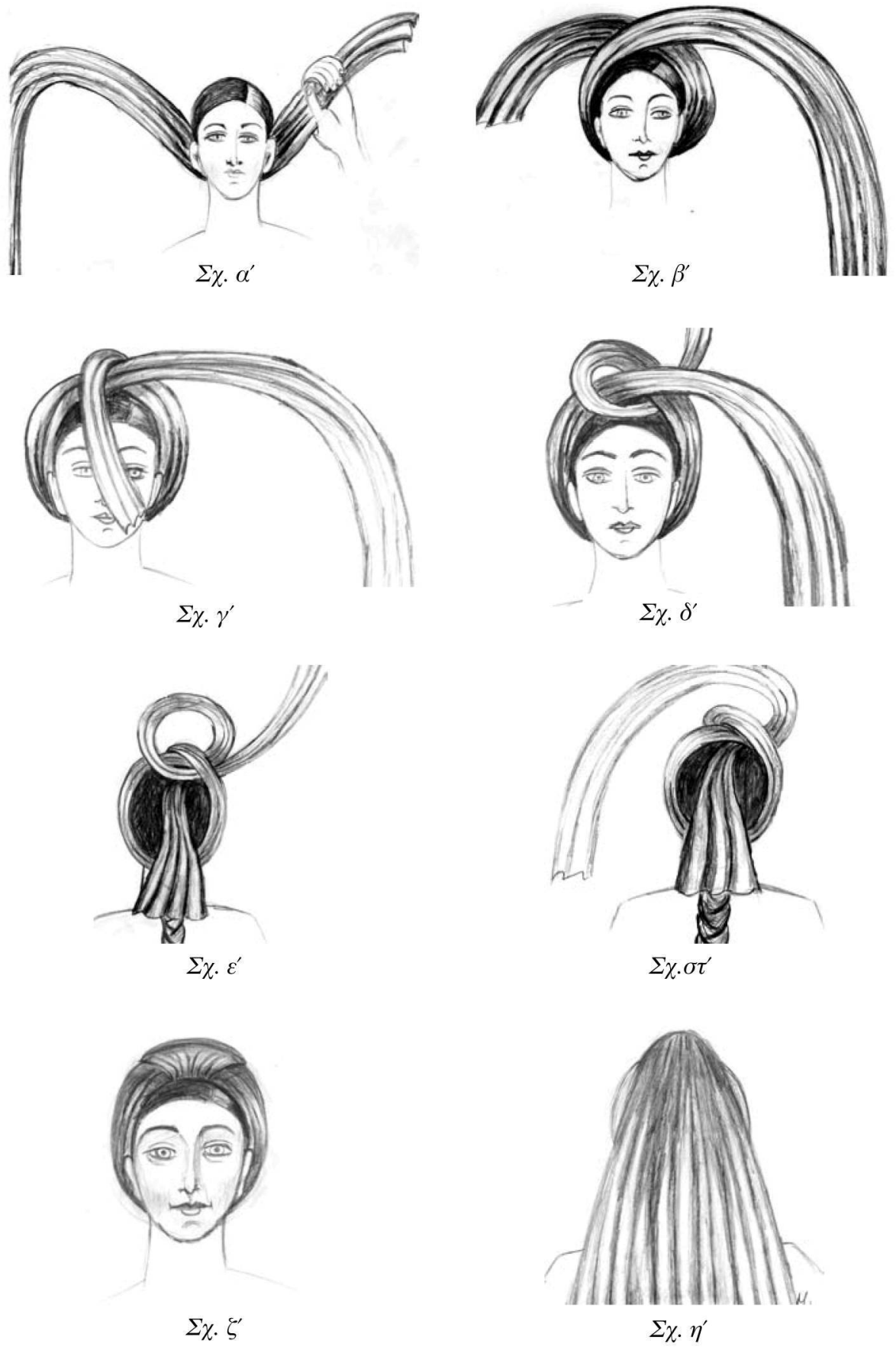